\title{
A population of Pax7-expressing muscle progenitor cells show differential responses to muscle injury dependent on developmental stage and injury extent
}

\author{
Stefanie Knappe ${ }^{1}$, Peter S. Zammit ${ }^{2}$ and Robert D. Knight ${ }^{1 *}$ \\ 'Department of Craniofacial Development and Stem Cell Biology, Dental Institute, King's College London, London, UK, \\ ${ }^{2}$ Randall Division of Cell and Molecular Biophysics, Faculty of Life Sciences and Medicine, King's College London, London, UK
}

OPEN ACCESS

Edited by:

Jaime J. Carvajal,

Centro Andaluz de Biología del

Desarrollo, Spain

Reviewed by:

Bogdan O. Popescu,

Colentina Clinical Hospital, Romania

Itamar Harel,

Stanford School of Medicine, USA

*Correspondence:

Robert D. Knight,

Department of Craniofacial

Development and Stem Cell Biology,

Dental Institute, King's College

London, Guy's Hospital Campus,

Guy's Hospital Tower Wing Floor 27,

Great Maze Pond, London SE1 9RT,

robert.knight@kcl.ac.uk

Received: 13 April 2015 Accepted: 06 August 2015

Published: 25 August 2015

Citation:

Knappe S, Zammit PS and Knight RD (2015) A population of

Pax7-expressing muscle progenitor cells show differential responses to muscle injury dependent on developmental stage and injury extent.

Front. Aging Neurosci. 7:161

doi: 10.3389/fnagi.2015.00161
Skeletal muscle regeneration in vertebrates occurs by the activation of quiescent progenitor cells that express pax 7 to repair and replace damaged myofibers. We have developed a mechanical injury paradigm in zebrafish to determine whether developmental stage and injury size affect the regeneration dynamics of skeletal muscle. We found that both small focal injuries, and large injuries affecting the entire myotome, lead to expression of myf5 and myogenin, which was prolonged in older larvae, indicating a slower process of regeneration. We characterized the endogenous behavior of a population of muscle-resident Pax7-expressing cells using a pax7a:eGFP transgenic line and found that GFP+ cell migration in the myotome dramatically declined between 5 and 7 days post-fertilization (dpf). Following a small single myotome injury, GFP+ cells responded by extending processes, before migrating to the injured myofibers. Furthermore, these cells responded more rapidly to injury in $4 \mathrm{dpf}$ larvae compared to $7 \mathrm{dpf}$. Interestingly, we did not see GFP+ myofibers after repair of small injuries, indicating that pax7a-expressing cells did not contribute to myofiber formation in this injury context. On the contrary, numerous GFP+ myofibers could be observed after an extensive single myotome injury. Both injury models were accompanied by an increased number of proliferating GFP+ cells, which was more pronounced in larvae injured at $4 \mathrm{dpf}$ than $7 \mathrm{dpf}$. This indicates intriguing developmental differences, at these early ages. Our data also suggests an interesting disparity in the role that pax7a-expressing muscle progenitor cells play during skeletal muscle regeneration, which may reflect the extent of muscle damage.

Keywords: regeneration, stem cells, myogenesis, zebrafish, satellite cells, skeletal muscle, wound healing

\section{Introduction}

Skeletal muscle is a complex tissue consisting of multinuclear, contractile muscle fibers, yet it has a robust regenerative capacity through the action of muscle stem cells (muSCs). In mouse, the principle cells responsible for repairing or replacing damaged muscle are satellite cells (SCs). These were first described in frog and rat in 1961 (Mauro, 1961), and have since been described in most vertebrate species, including fish and other rodents 
(Moss and Leblond, 1970; Schultz et al., 1978; Koumans et al., 1990; Stoiber and Sänger, 1996). Generally, these tissueresident stem cells are located beneath the basal lamina of muscle fibers and show a characteristically large, heterochromatic nucleus in their quiescent state. Genetically, quiescent muSCs are characterized by expression of the paired homeobox transcription factor Pax7 (Seale and Rudnicki, 2000). It has been shown that Pax7-deficient muSCs show a loss of heterochromatin in their nucleus, suggesting the transcription factor is essential for maintaining quiescence (Gunther et al., 2013).

Pax7-expressing muSCs originate in the dermomyotome during embryogenesis, which contributes to the formation of skeletal muscle tissue in the trunk (Kassar-Duchossoy et al., 2004; Gros et al., 2005; Relaix et al., 2005). Their activation in post-natal animals can be induced by many stimuli, most notably mechanical injury. Activated and proliferating muSCs are characterized by the expression of the myogenic regulatory factors (MRFs) Myf5 and MyoD and later express Myogenin upon differentiation. A subset of these cells can undergo asymmetric cell division, giving rise to one progenitor and one differentiating daughter cell (Zammit et al., 2004; Shinin et al., 2006; Conboy et al., 2007). These cells are essential for maintenance and repair of skeletal muscle tissue and loss of Pax7 results in an impaired regenerative response after injury (Lepper et al., 2011; Sambasivan et al., 2011; Von Maltzahn et al., 2013). They regenerate injured muscle predominantly by either fusing to damaged muscle fibers, or to each other to form de novo muscle fibers. In mammals, newly formed myofibers generally have a smaller diameter and show myonuclei located centrally, as opposed to their usual location at the periphery of the myofiber.

Much of our understanding of how skeletal muscle regenerates comes from studies performed in the mouse. In fish, the presence of muSCs has been demonstrated in adult muscle tissue in a number of species including salmon, carp, and electric fish (Nag and Nursall, 1972; Akster, 1983; Weber et al., 2012). Extraction of muSCs from adult zebrafish also reveals that these cells show immunoreactivity for Pax7 and can form muscle fibers in culture (Alexander et al., 2011; Zhang and Anderson, 2014). Tissue regeneration in adult zebrafish has been described to occur within 28 days and involves the formation of regenerative fibers in conjunction with BrdU labeling, indicating proliferating progenitor cells (Rowlerson et al., 1997).

Investigations into the developmental origin of pax $7+$ cells in zebrafish larvae revealed that they originate from the dermomyotome, similarly to amniotes (Hollway et al., 2007; Marschallinger et al., 2009). These cells are mitotically inactive and express several typical muSC markers, such as cxcr4 genes (Hollway et al., 2007) and Syndecan-4 (Froehlich et al., 2013). Further, muscle regeneration occurs through de novo formation of new fibers and not, as previously assumed, by dedifferentiation in larval animals (Rodrigues et al., 2012). Further, muSCs have also been shown to respond to injury stimuli by migrating to, and proliferating at, the site of injury in zebrafish larvae (Seger et al., 2011; Otten et al., 2012).

The majority of studies examining muSC function have been performed in mouse using models, such as cardiotoxin or barium chloride, inducing fairly major injuries. Considering recent evidence from the skin, which indicates that the response of hair follicle stem cells differs depending on the magnitude of injury (Chen et al., 2015), we aimed to investigate whether this could also be true for muSCs. We have therefore investigated how Pax7-expressing cells respond to muscle injury using a transgenic zebrafish line in which the pax7a promoter drives eGFP expression. We have defined two protocols for creating precise muscle damage and characterized the process of injury healing using immunohistochemistry, in situ hybridization and in vivo imaging. We find that, although pax7a-expressing (GFP) cells in this line respond to injury, it is the extent of damage that determines whether they form new muscle fibers. Furthermore, we find that the developmental stage may have an impact on the speed of regeneration and the response of pax7a-expressing cells to injury.

\section{Materials and Methods}

\section{Zebrafish}

Adult zebrafish were maintained according to standard procedures (Westerfield, 2000) in a $12 \mathrm{~h}$ light/dark cycle. All animal work was carried out in accordance with the Animals (Scientific Procedures) Act 1986. Embryonic fish were maintained in $\mathrm{E} 3$ medium at $28^{\circ} \mathrm{C}$. After $5 \mathrm{dpf}$, E3 medium was changed and larvae fed with Gemma75 (Skretting) daily.

The Tg[pax7a:eGFP] transgenic line was a kind gift from Christiane Nüsslein-Volhardt (Max-Planck Institute for Developmental Biology, Tübingen, Germany) and has been described previously (Mahalwar et al., 2014). This line was maintained in a homozygous pfeffer ( $p f e$, allele tm36b) mutant background (Odenthal et al., 1996). pfe fish form fewer pax7a:eGFP transgene-expressing xanthophore pigment cells in the skin due to a mutation in the $f m s / c s f r-1$ gene (Parichy et al., 2000; Maderspacher and Nusslein-Volhard, 2003). pax7a:eGFP;pfe were crossed with double mutant roy;mitfa (caspar) mutants (White et al., 2008). The F2 offspring were maintained as homozygous pfe;mitfa mutants carrying the pax7a:eGFP transgene (subsequently referred to as pax7a:eGFP).

\section{Mechanical Injury}

Larvae were anesthetized in 0.01\% MS-222 (Sigma) in E3 embryo medium and embedded laterally in $1.5 \%$ low melting agarose (Sigma) as previously described (Westerfield, 2000).

For small injuries, tungsten wire (diameter $0.125 \mathrm{~mm}$, GoodFellow) was sharpened by electrolysis in potassium hydroxide. Wire was then cleaned and polished using a pair of fine forceps, inserted into a needle holder and fixed into a microinjection rig. Injuries were targeted to the center of the 12th ventral myotome. Approximate depth of injuries was $0.1 \mathrm{~mm}$ within a single myotome.

For extensive injuries, tungsten wire was replaced by an unsharpened steel manipulation needle (diameter $1 \mathrm{~mm}$ ). Three adjacent puncture wounds were targeted to the 12th ventral myotome and the needle was agitated from a medial to distal position in order to damage as many muscle fibers as possible.

For recovery, free-swimming larvae were maintained as above. To assess proliferation, larvae were incubated in $10 \mathrm{mM} \mathrm{BrdU}$ 
(Sigma) 1\% DMSO in E3 embryo medium for the duration of recovery.

\section{Immunohistochemistry}

For GFP/phalloidin staining, larvae were anesthesized in $0.02 \%$ MS-222 and fixed in 4\% paraformaldehyde (PFA, Sigma) for $1 \mathrm{~h}$ at room temperature. Samples were washed in $0.1 \%$ Tween 20 in phosphate-buffered saline (PBT, Sigma) and permeabilized in $100 \%$ acetone for $30 \mathrm{~min}$ at $-20^{\circ} \mathrm{C}$. After several washes in PBT, samples were blocked in 5\% goat serum (Life Technologies) in PBT for at least $2 \mathrm{~h}$, then incubated with primary antibody diluted in $5 \%$ goat serum/PBT over night at $4^{\circ} \mathrm{C}$. Samples were washed for at least $4 \mathrm{~h}$ in $0.1 \%$ PBT the following day, then incubated with secondary antibodies diluted in 5\% goat serum/PBT for $2 \mathrm{~h}$ at room temperature. After several washes in PBT, samples were taken through glycerol series and mounted in VectaShield with DAPI (Vector Laboratories).

For Pax7/GFP staining, larvae were fixed in 2\% PFA for $30 \mathrm{~min}$ at room temperature. Samples were washed in $1 \%$ Triton-X (Sigma) in PBS (1\% PBTx) and blocked in 5\% goat serum in $1 \%$ PBTx for at least $2 \mathrm{~h}$. Incubation with primary antibodies, diluted in $5 \%$ goat serum $/ 1 \%$ PBTx, was carried out for $48 \mathrm{~h}$ at room temperature. Samples were washed in 1\% PBTx and immunostained with secondary antibody diluted in 5\% goat serum/1\% PBTx over night at room temperature. Larvae were then washed in $1 \%$ PBTx, taken through glycerol series and mounted in VectaShield with DAPI.

For BrdU/GFP staining, larvae were fixed for $30 \mathrm{~min}$ in $2 \%$ PFA at room temperature and subsequently stored in $100 \%$ methanol (Fisher) over night at $-20^{\circ} \mathrm{C}$. The next day, larvae were taken through a re-hydration series of methanol/PBS and washed in $1 \%$ PBTx. Following, the samples were permeabilized in $10 \mu \mathrm{g} / \mathrm{ml}$ of proteinase $\mathrm{K}$ in $0.1 \%$ PBT for $1 \mathrm{~h}$ at room temperature. After several washes in $0.1 \% \mathrm{PBT}$, samples were incubated in $2 \mathrm{~N} \mathrm{HCl}$ (Sigma) in $\mathrm{H}_{2} \mathrm{O}$ for $1 \mathrm{~h}$. Samples were subsequently washed with $1 \% \mathrm{DMSO} / 0.1 \%$ Tween 20 in PBS (PBDT) and blocked in 5\% goat serum in PBDT for at least $2 \mathrm{~h}$ at room temperature. Incubation with primary antibodies, diluted in $5 \%$ goat serum in PBDT, was carried out over night at $4^{\circ} \mathrm{C}$. After several washes in PBDT, larvae were incubated in secondary antibodies, diluted in 5\% goat serum in PBDT, for $2 \mathrm{~h}$ at room temperature. Samples were then washed, taken through glycerol series and mounted in VectaShield with DAPI.

Primary antibodies used: rabbit polyclonal anti-GFP (1:500; Life Technologies), mouse polyclonal anti-Pax7 (1:5, DSHB), rat monoclonal anti-BrdU (1:200, Abcam).

Secondary antibody used: goat anti-rabbit IgG AlexaFluor488 conjugated (1:500; Life Technologies), goat anti-mouse IgG AlexaFluor568 conjugates (1:500, Life Technologies), goat antirat IgG AlexaFluor568 conjugated (1:500, Life Technologies), fluorophore-conjugated phalloidin555 (1:300; PromoKine).

\section{In situ Hybridization}

In situ hybridization was performed as described previously (Thisse and Thisse, 2008) with the following modifications. Larvae were permeabilized in a $100 \mu \mathrm{g} / \mathrm{ml}$ solution of collagenase (Sigma, stock solution of $1 \mathrm{mg} / \mathrm{ml}$ in Ringer's solution, diluted
$1: 10$ in $0.1 \%$ PBT) for $2 \mathrm{~h}$ at room temperature prior to hybridization with riboprobe. For hybridization, DIGconjugated riboprobes to myf5 (Groves et al., 2005) and myogenin (Weinberg et al., 1996) were used, which were detected using alkaline phosphatase conjugated FAB fragments (Roche). After detection, samples were developed in $0.25 \%$ NBT/BCIP in PBT (Sigma) for 7 days, then post-fixed in $4 \%$ PFA for $30 \mathrm{~min}$, taken through glycerol series and mounted for analysis

Expression was quantified by eye and expression classified as either present or absent in the injured myotome. For all experiments, 10 larvae were used per condition and animals showing poor health after injury excluded from subsequent analyses. We then calculated the number of animals showing expression per condition as a percentage to compensate for any differences in overall number.

\section{Injury Volume Measurements}

Samples were scanned using a Leica TCS SP5 microscope equipped with a Leica CTR 6500 laser and LAS AF software and subsequently analyzed using ImageJ/ Fiji (Schindelin et al., 2012). The area of injured muscle and resulting gaps between myofibers was selected using the Fiji ROI tool for each slice in a z-stack and measured using "ROI manager." The area of each slice was then multiplied by the slice thickness and summed to obtain the total volume of injury in $\mu \mathrm{m}^{3}$.

\section{Individual Cell Tracking and Counting}

For time-lapsed recordings, larvae were embedded laterally in $1.5 \%$ low-melting agarose. A Nikon D-Eclipse C1 microscope with $488 \mathrm{~nm}$ argon laser, EZ-C1 3.70 software and $\mathrm{x} 40$ water dipping objective was used. Z-stacks were acquired in $1 \mu \mathrm{m}$ steps with upper limit at the skin and lower limit at the neural tube. Z-stacks were acquired every $30 \mathrm{~min}$ and were $8-14 \mathrm{~h}$ in total duration. Time-lapsed data was processed entirely in ImageJ/Fiji. Drift was adjusted using the "Correct 3D drift" plugin, single cells were tracked manually using the "MtrackJ" plugin.

For cell counting, immunostained samples were scanned at the level of the 12th ventral myotome using a Leica confocal microscope and analyzed using Image J/Fiji. Individual DAPI+ cells in z-stacks were counted using the "Cell counter" plugin. For control larvae, cells in the uninjured 12th ventral myotome were counted.

\section{Data Analysis}

All plots and statistical analyses were generated using IBM SPSS Statistics 21 .

\section{Results}

\section{Small Single Myotome Injury: A Reproducible Mechanical Injury Paradigm in Zebrafish Larvae}

Previous approaches to model muscle injury in zebrafish larvae involved the injection of cardiotoxin (chemical injury; Seger et al., 2011) and tail transection (large mechanical injury; Rodrigues et al., 2012). We were interested in investigating regeneration dynamics in response to a targeted mechanical injury to a 
small number of muscle fibers, and used a sharpened tungsten wire fixed into a microinjection rig. We analyzed injuries using fluorophore-conjugated phalloidin to stain F-actin in muscle fibers and so provide the means to visualize the injury. This revealed that several myofibers in the targeted myotome showed signs of tearing and hyper-contraction (indicated by brighter phalloidin staining), while all muscle fibers in neighboring myotomes were unaffected (Figure 1A). Furthermore, the injury was precisely targeted to avoid damaging the vertical or central myosepta (see asterisk in the orthogonal view in Figure 1A).

To analyze the extent and reproducibility of our small single myotome injury paradigm, we measured the total volume of the injury at 1 hours post injury (hpi) ( $n=14$ larvae; Figure 1B). As shown in (Figures 1C,D), most injury volumes were between $5 \times 10^{4}$ and $1.5 \times 10^{5} \mu \mathrm{m}^{3}$ (11/14 larvae). Thus, a controlled injury using a sharpened tungsten wire results in a reproducible muscle wound contained within a single myotome, which can be used for evaluating the process of muscle regeneration in vivo. We termed this injury model a "small single myotome injury."

\section{Small Single Myotome Injuries Are Rapidly Repaired}

We next analyzed the size of the small single myotome injury in phalloidin-stained larvae at defined intervals after injury. Injury was performed on larvae at 4 or $7 \mathrm{dpf}$ to also examine whether muscle repair was affected by developmental stage (Figure 2A). At $1 \mathrm{hpi}$, the injured myotome in $7 \mathrm{dpf}$ larvae resembled that in $4 \mathrm{dpf}$ fish, with hyper-contracted, and torn myofibers easily distinguishable from undamaged muscle fibers. After $24 \mathrm{~h}$, large gaps were visible between myofibers in superficial and deep portions of the myotome, regardless of larva age at injury. Such gaps were never observed in adjacent, un-targeted ventral myotomes. While these gaps largely disappeared by $48 \mathrm{hpi}$ in the superficial myotome of larvae injured at $4 \mathrm{dpf}$, they occasionally persisted in larvae injured at $7 \mathrm{dpf}$. Furthermore, it was noticeable that the gaps were still present in the more central regions of the myotome in larvae injured at either age. By $96 \mathrm{hpi}$, gaps in the central portion of the myotome were no longer present. Interestingly, in larvae injured at $7 \mathrm{dpf}$, the

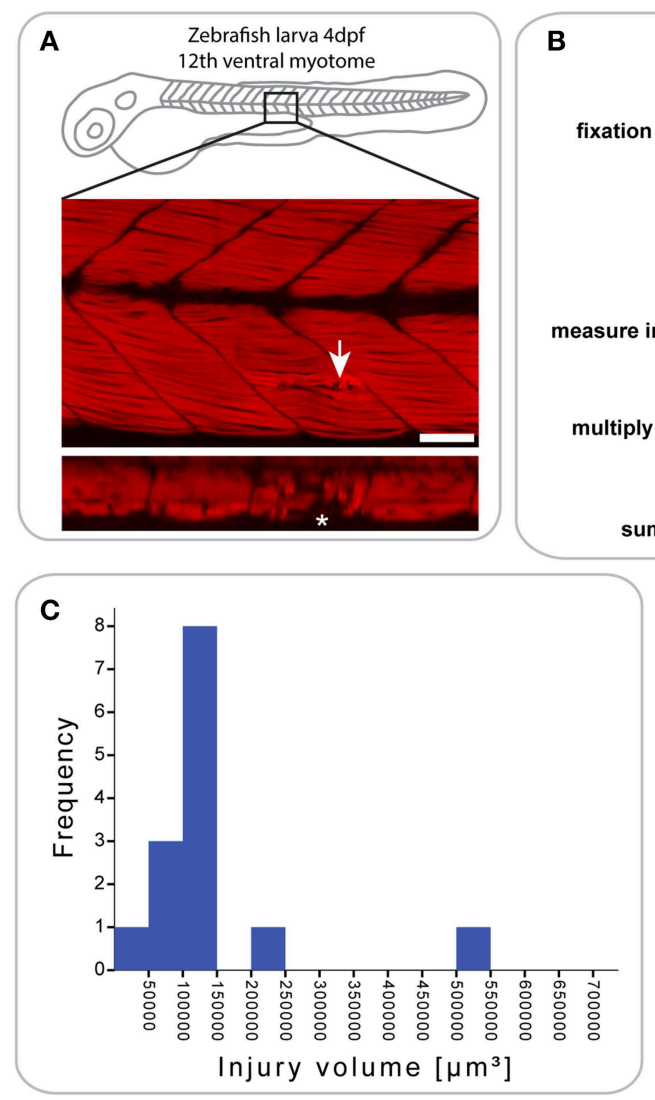

FIGURE 1 | Defining a reproducible mechanical injury paradigm in the zebrafish larva. (A) Confocal slice of larvae injured in the 12th ventral myotome at 4 days post-fertilization (dpf) and immunostained for phalloidin (F-actin) at $1 \mathrm{~h}$ post-injury (hpi). Arrowhead indicates site of injury. Panel of orthogonal XZ view centered on the injury site is shown beneath and injury site is indicated by an asterisk. Left is anterior, top is dorsal, scale bar is $50 \mu \mathrm{m}$. (B) Workflow for the quantification of injury size. After immunostaining and confocal imaging of injured larvae, the injured muscle, and resulting gaps between myofibers were circled using Fiji ROI tool on each slice and the area measured. This is illustrated by the images shown on the right, which present the phalloidin-stained site of injury with $\mathrm{ROI}$ contours in yellow. The area of each slice was then multiplied by the slice thickness and all slices summed to obtain the total volume of injury in $\mu \mathrm{m}^{3}$, illustrated by the images on the right. (C) Histogram showing the distribution of injury volume at $1 \mathrm{hpi}$ for $n=14$ larvae injured at $4 \mathrm{dpf}$. Most samples cluster around an injury volume of $100,000 \mu \mathrm{m}^{3}$. (D) Scatter plot for the same dataset, plotting the injury volume for each of the 14 samples. 

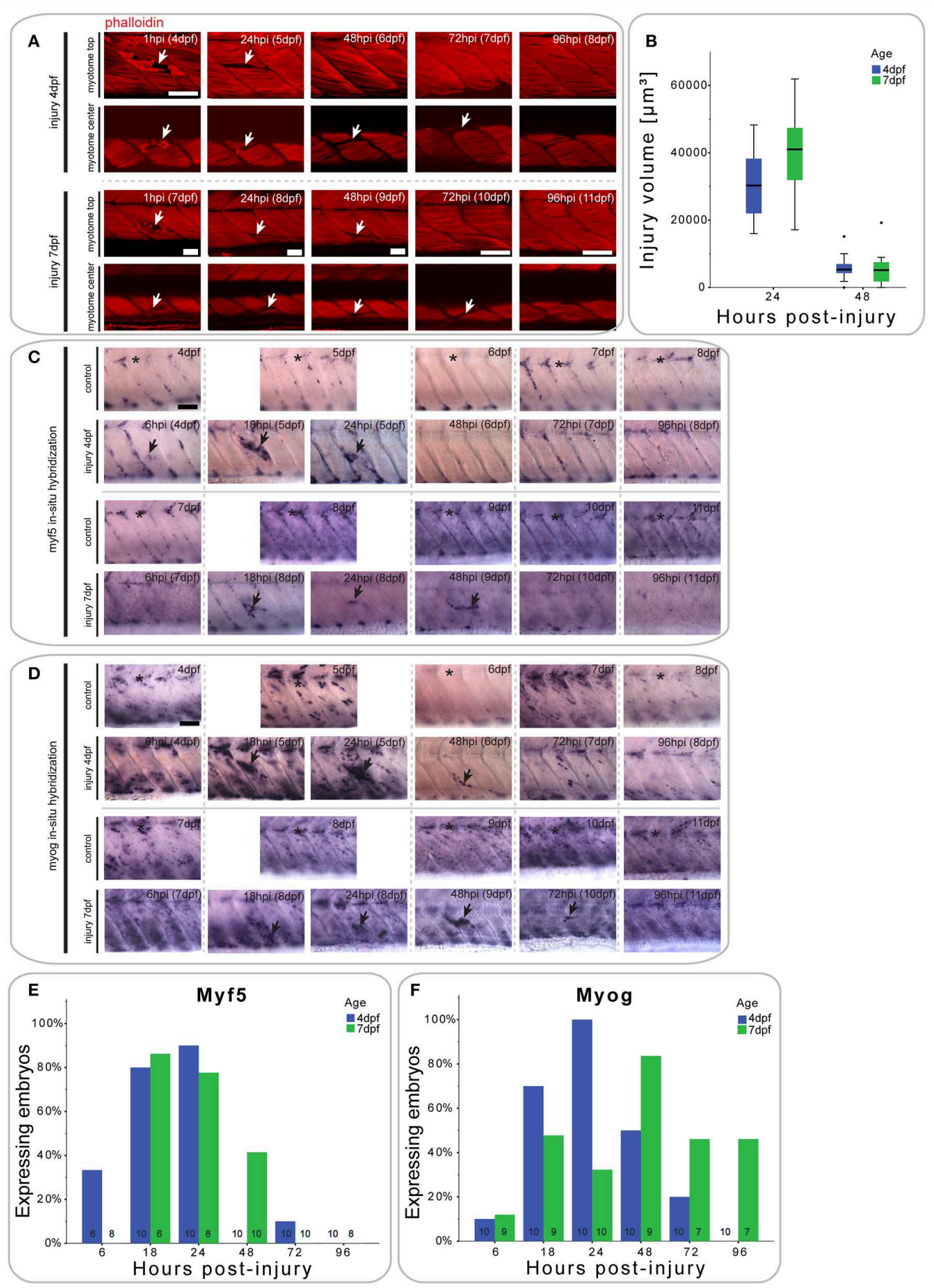

FIGURE 2 | Small single myotome injuries are rapidly repaired and result in characteristic expression of MRFs. (A) Confocal slices of the superficial and deep 12th ventral myotome of larvae injured at 4 or $7 \mathrm{dpf}$ and stained for phalloidin (f-actin) after injury. Arrowheads indicate site of injury. (B) Quantification of injury volume at varying time-points post-injury in larvae injured at 4 or $7 \mathrm{dpf}$. Injury volume was measured as described in Figure 1B. $p<0.005$ for differences in injury volume between 24 and $48 \mathrm{hpi}$ independent of age; $p=0.223$ for differences in injury volume between 4 and $7 \mathrm{dpf}$ independent of hpi; $p=0.158$ for differences in injury volume dependent on age and hpi. (C,D) Representative images of in situ hybridization with myf5 (C) or myogenin (D) anti-sense probe of uninjured controls and larvae injured in the 12th ventral myotome at 4 or $7 \mathrm{dpf}$ at various time-points post-injury. The 12th myotome is marked by an asterisk in control images. Arrowheads indicate expression patterns of note in injured samples. Left is anterior, top is dorsal, scale bar is $50 \mu \mathrm{m}$ for all images. (E,F) Bar graph showing the proportion of embryos expressing myf5 (E) and myogenin (F) at the site of injury at different time-points post-injury. Small numbers on bars indicate the total number of larvae. 
upper myotome was largely repaired by $72 \mathrm{hpi}$, but still exhibited slight distortion. To identify whether there were differences in muscle repair initiated at 4 or $7 \mathrm{dpf}$, we measured the volume of injury at 24 and 48 hpi (Figure 2B). Even though there was no significant difference between larvae injured at 4 or $7 \mathrm{dpf}$, the average injury volume of $4 \mathrm{dpf}$ larvae was smaller. At $48 \mathrm{hpi}$, the injury volume of $7 \mathrm{dpf}$ larvae showed a larger distribution.

\section{Expression Profile of myf5 during Repair Following Small Single Myotome Injury}

Despite the visible reduction in injury size and apparent repair of the muscle, regenerating myofibers were not observed close to the original site of injury (Figure 2A). To understand how myogenesis is regulated during muscle repair, we characterized expression of MRFs using in situ hybridization.

Larvae injured at $4 \mathrm{dpf}$ showed a small increase in myf5 expression in the injured myotome at $6 \mathrm{hpi}(2 / 6$ larvae), which peaks between 18 hpi (8/10 larvae) and 24 hpi $(9 / 10$ larvae) (Figure 2C, quantified in Figure 2E). By 48 hpi, myf5 was no longer expressed in the injured myotome $(0 / 10$ larvae).

In larvae injured at $7 \mathrm{dpf}, m y f 5$ expression was not detected in the injured myotome at $6 \mathrm{hpi}(0 / 10$ larvae), but was elevated at 18 hpi (5/6 larvae) (Figure 2C, quantified in Figure 2E). myf5 expression further increased at $24 \mathrm{hpi}$ (6/8 larvae), though seemed less pronounced than in larvae injured at $4 \mathrm{dpf}$. Expression persisted at $48 \mathrm{hpi}$ (4/10 larvae) in $7 \mathrm{dpf}$ larvae, which was not the case in larvae injured at $4 \mathrm{dpf}$. After $72 \mathrm{hpi}$, myf5 was no longer expressed in the injured myotome of $7 \mathrm{dpf}$ larvae (1/10 larvae).

\section{Expression Profile of Myogenin during Repair Following Small Single Myotome Injury}

To identify cells initiating myogenic differentiation, we also investigated the expression of myogenin after injury. Six hours after injury, there was no noticeable myogenin expression in the injured myotome of $4 \mathrm{dpf}$ larvae (1/10 larvae) (Figure 2D, quantified in Figure 2F). myogenin became detectable at 18 hpi (7/10 larvae) and was subsequently up-regulated at $24 \mathrm{hpi}$ (10/10 larvae). Expression then gradually decreased between 48 hpi (5/10 larvae) and 72 hpi (3/10 larvae) and was back to background levels at $96 \mathrm{hpi} \mathrm{(0/10} \mathrm{larvae).}$

Similarly, myogenin expression was not elevated in the targeted myotome of $7 \mathrm{dpf}$ larvae at $6 \mathrm{hpi}$ (1/9 larvae) (Figure 2D, quantified in Figure 2F). Interestingly, expression of myogenin appeared at a slower rate in the older larvae, with only slightly elevated expression at $24 \mathrm{hpi} \mathrm{(3/10} \mathrm{larvae).} \mathrm{Expression} \mathrm{peaked}$ only at $48 \mathrm{hpi} \mathrm{(7/9} \mathrm{larvae)} \mathrm{and} \mathrm{persisted} \mathrm{until} 72 \mathrm{hpi} \mathrm{(3/10} \mathrm{larvae)}$ and 96 hpi (3/7 larvae).

Thus, repair of muscle fibers in zebrafish larvae with small single myotome injury involves an initial expression of myf5 at the injury site, followed by myogenin, with myf5 and myogenin persisting longer in repairing muscle in larvae injured at $7 \mathrm{dpf}$, compared to those injured at $4 \mathrm{dpf}$.

\section{The Extensive Single Myotome Injury Model Reveals That Muscle Regeneration Dynamics Are Affected by Injury Extent}

To test whether the size of injury affects muscle regeneration, we also developed an extensive single myotome injury paradigm, using an unsharpened steel manipulation needle which damaged at least $50 \%$ of myofibers in the targeted myotome. Muscle injuries were analyzed by staining for F-actin using fluorophoreconjugated phalloidin. Following injury at $4 \mathrm{dpf}$, no damaged muscles fibers remained in the injured myotome after $24 \mathrm{~h}$ (Figure 3A). The injured myotome was filled with cells as shown by DAPI labeling (data not shown). Small diameter regenerating myofibers appeared between 72 and 144 hpi. Despite regeneration of muscle fibers, the injured myotome remained mildly deformed and smaller in size than adjacent myotomes 6 days after injury.

In larvae injured at $7 \mathrm{dpf}$, most damaged myofibers were cleared by 24 hpi (Figure 3A). Regenerating myofibers first become visible between 72 and $144 \mathrm{hpi}$, though they were visibly less numerous than in larvae injured at $4 \mathrm{dpf}$. Six days post-injury, the injured myotome was still visibly distorted.

\section{Expression Profile of myf5 during Regeneration Following Extensive Single Myotome Injury}

In larvae injured at $4 \mathrm{dpf}$, myf5 expression was undetected at the site of injury at $6 \mathrm{hpi}(0 / 10$ larvae) (Figure 3B, quantified in Figure 3D). Expression was greatly up-regulated at $18 \mathrm{hpi}$ (10/10 larvae) and remained at high levels through $24 \mathrm{hpi} \mathrm{(10/10}$ larvae) and 48 hpi (10/10 larvae). It was also apparent in brightfield images that the size of the injured myotome was reduced at 48 hpi relative to adjacent uninjured myotomes. Expression of myf5 decreased at 72 hpi (9/10 larvae), although it remained above endogenous levels at $96 \mathrm{hpi}$ in the injured myotome $(10 / 10$ larvae). Finally, myf5 further decreased at 120 hpi (7/10 larvae) and was reduced to levels comparable to controls by $144 \mathrm{hpi} \mathrm{(4/10}$ larvae).

A similar profile of myf5 expression was observed in larvae that underwent extensive single myotome injury at $7 \mathrm{dpf}$. There was no myf5 detectable in the injured myotome at 6 hpi $(0 / 6$ larvae) (Figure 3B, quantified in Figure 3D). At $18 \mathrm{hpi}$, myf5 expression was observed in the injured myotome, particularly around the edges (9/10 larvae). Expression increased by $24 \mathrm{hpi}$ (8/8 larvae) and was robust at the site of injury at $48 \mathrm{hpi}(9 / 9$ larvae). As in larvae injured at $4 \mathrm{dpf}$, the size of the myotome was visibly reduced at 48 hpi. Subsequently, expression levels of myf5 decreased but remained detectable between 72 hpi (9/9 larvae) and $96 \mathrm{hpi} \mathrm{(5/5} \mathrm{larvae).} \mathrm{In} \mathrm{contrast} \mathrm{to} \mathrm{larvae} \mathrm{injured} \mathrm{at}$ $4 \mathrm{dpf}$, larvae injured at later stages maintain higher levels of myf5 expression at the injury site at $120 \mathrm{hpi} \mathrm{(8/10} \mathrm{larvae)} \mathrm{and} 144 \mathrm{hpi}$ (6/8 larvae).

\section{Expression Profile of Myogenin during Regeneration Following Extensive Single Myotome Injury}

The differentiation marker myogenin is not expressed in the injured myotome at $6 \mathrm{hpi}$ in $4 \mathrm{dpf}$ larvae (0/10 larvae) (Figure 3C, quantified in Figure 3E). Slight expression was visible at $18 \mathrm{hpi}$ 

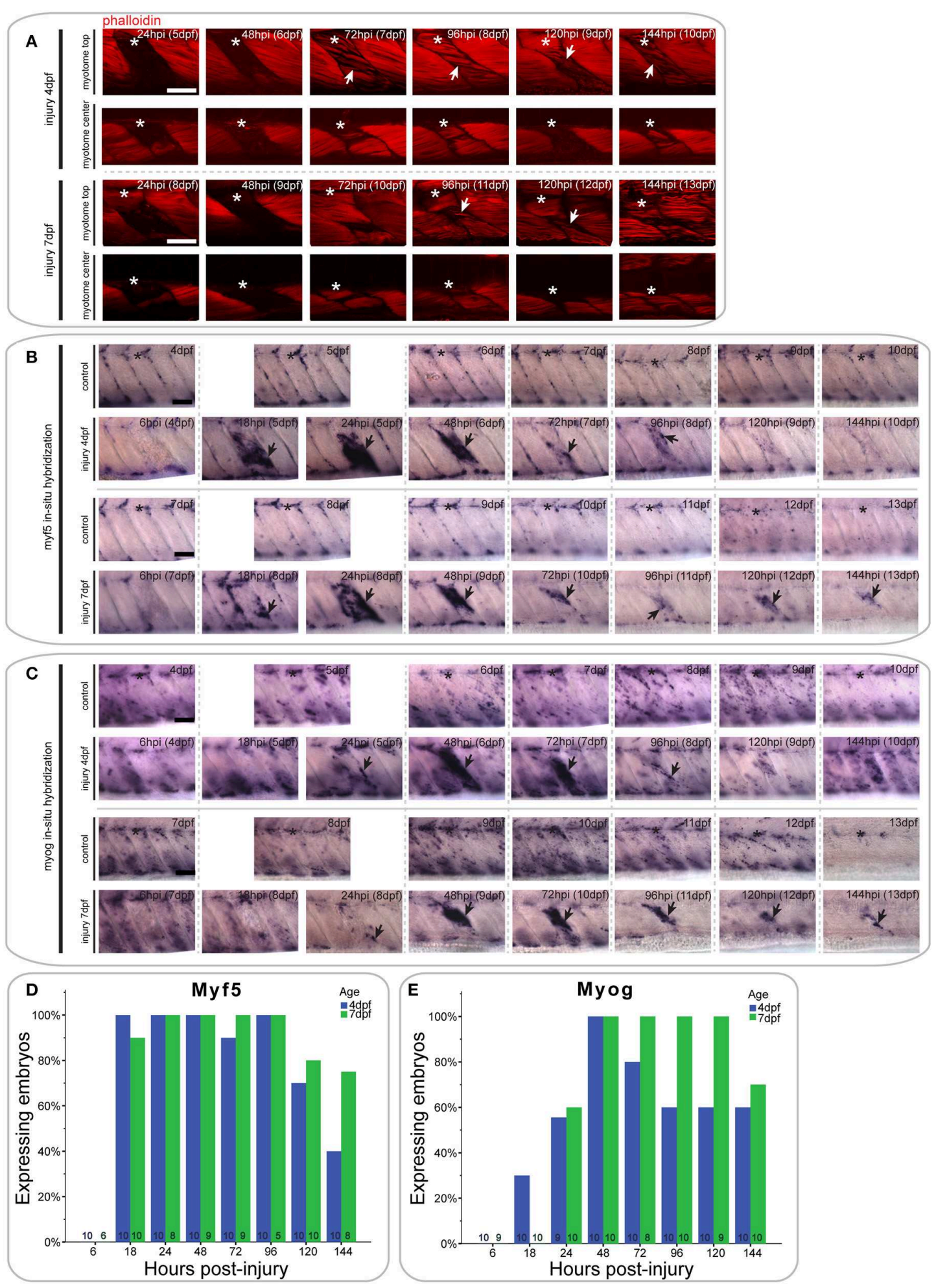

FIGURE 3 | Extensive single myotome injuries are rapidly regenerated and result in characteristic expression of MRFs. (A) Confocal slices of the superficial and deep 12th ventral myotome of larvae with an extensive single myotome injury at 4 or $7 \mathrm{dpf}$ and stained for phalloidin (f-actin) after injury. Asterisk indicates injured myotome, arrowheads indicate structures of note. (B,C). Representative images of in situ hybridization using myf5 (B) or myogenin (C) anti-sense probe of uninjured controls and larvae injured extensively in the 12th ventral myotome at 4 or $7 \mathrm{dpf}$ at various time-points post-injury. The 12th myotome is marked by an asterisk in control images. Arrowheads indicate expression patterns of note in injured samples. Left is anterior, top is dorsal, scale bar is $50 \mu \mathrm{m}$ for all images. (D,E) Bar graph showing the proportion of embryos expressing myf5 (D) or myogenin (E) at the site of injury at different time-points post-injury. Small numbers on bars indicate the total number of larvae. 
(3/10 larvae) and 24 hpi (5/9 larvae). myogenin expression was then greatly increased at $48 \mathrm{hpi}(10 / 10$ larvae), and remained at a high level through to $72 \mathrm{hpi}$ (8/10 larvae). Myogenin expression was reduced at $96 \mathrm{hpi}(6 / 10$ larvae) and then remained at a constant level in the regenerating myotome through $120 \mathrm{hpi}$ (6/10 larvae) and 144 hpi (6/10 larvae).

Larvae injured at $7 \mathrm{dpf}$ had a very similar myogenin expression profile to those injured at $4 \mathrm{dpf}$. There was little detectable expression in the injured myotome at $6 \mathrm{hpi} \mathrm{(0/9} \mathrm{larvae)} \mathrm{and}$ 18 hpi (0/10 larvae) (Figure 3C, quantified in Figure 3E). Small groups of cells started to express myogenin around the site of injury at $24 \mathrm{hpi}$ (6/10 larvae). Expression then strongly increased between 48 hpi (10/10 larvae) and 72 hpi (8/8 larvae). Compared to larvae injured at $4 \mathrm{dpf}$, myogenin expression was stronger at $96 \mathrm{hpi}$ and still prominent around the wound site (10/10 larvae). Similarly, expression levels of myogenin were still markedly elevated at $120 \mathrm{hpi} \mathrm{(9/9} \mathrm{larvae)} \mathrm{and} 144 \mathrm{hpi}$ (7/10 larvae) in larvae injured at $7 \mathrm{dpf}$.

Thus, larvae injured at 4 or $7 \mathrm{dpf}$ are both able to partially regenerate muscle following an extensive single myotome injury, which damages the majority of a myotome. However, larvae injured at $7 \mathrm{dpf}$ appear to regenerate fewer myofibers than those injured at $4 \mathrm{dpf}$ and show prolonged expression of MRFs throughout the course of regeneration.

\section{pax7a-expressing Cells in the Myotome Display Developmental-Dependent Changes in Their Behavior}

We hypothesized that the delayed regenerative response in $7 \mathrm{dpf}$ larvae relative to that in $4 \mathrm{dpf}$ larvae could be caused by a developmental change in muSC behavior. To investigate this, we used a transgenic line in which eGFP is expressed under control of a pax7a promoter (pax7a:eGFP; Mahalwar et al., 2014). In this line, we note that there were many GFP+ cells localized at the myoseptum, where Pax7+ cells have previously been described during zebrafish development and have been shown to be recruited to sites of muscle injury (Devoto et al., 2006; Hollway et al., 2007; Seger et al., 2011).

To first understand how pax7a+ cells behave during different stages of muscle development, we characterized GFP+ cell movement in pax7a:eGFP larvae between 3 and $7 \mathrm{dpf}$ using time-lapsed microscopy (Figures 4A-C, Videos S1-S3).

At $3 \mathrm{dpf}$, GFP + cells in pax7a:eGFP larvae were located at the horizontal and vertical myosepta as previously described for Pax7+ cells (Hollway et al., 2007; Seger et al., 2011). GFP+ cells at the vertical myosepta could occasionally be observed moving into the middle of the myotome, although the majority of the cells remained at the myosepta (Figure 4A). This movement was preceded by the extension of processes toward the middle of the myotome (Figure 4A, blue arrow), followed by cell migration (Figure 4A, yellow arrow). Cell division events could be observed at this stage (mean $=0.375$ divisions $/ \mathrm{h}, \mathrm{stdev}=0.177$ for $n=2$ larvae) and predominantly occurred at the myosepta (Figure 4A, green arrow).

In $5 \mathrm{dpf}$ pax7a:eGFP larvae, there was a more extensive movement of GFP+ cells (Figure 4B). Fewer cells appeared to be present at the myosepta and cells could be observed moving from this area toward the middle of the myotome (Figure 4B, yellow arrow). In the middle of the myotome, cells appeared to be moving along, or adjacent to, muscle fibers (Figure 4B, blue arrow). Further, cell division events occurred at $5 \mathrm{dpf}$ (mean $=0.5$ divisions $/ \mathrm{h}$, stddev $=0.303$ for $n=2$ larvae), but in the middle of the myotome (Figure 4B, green arrow; also in the upper left portion of the myotome at $5 \mathrm{~h}$ ).

GFP+ cell behavior differs entirely in pax7a:eGFP larvae at $7 \mathrm{dpf}$ (Figure 4C). Cells were located both at the myosepta and in the middle of the myotome, but did not show extensive movement, unlike at 3 or $5 \mathrm{dpf}$. Cells at the myosepta were generally of a rounded morphology and occasionally extended processes toward the middle of the myotome, but did not move from their myoseptal location (Figure $4 \mathrm{C}$, green and blue arrows). On the contrary, cells located in the middle of the myotome had an elongated morphology, aligned in the same orientation as muscle fibers. These cells did not move extensively along the myofibers, but occasionally their cell morphology changed (Figure 4C, yellow arrow). Furthermore, in contrast to 3 and $5 \mathrm{dpf}$, no cell divisions could be observed in $7 \mathrm{dpf}$ larvae (mean $=0$ for $n=2$ larvae).

To quantify GFP+ cell behavior during development in pax7a:eGFP larvae, cell movement in the myotome was analyzed in 3,5, and 7 dpf larvae through manual tracking (Figures 4D-F). This revealed that the average cell speed did not differ significantly between 3 and $5 \mathrm{dpf}$ larvae $(p=0.959)$, but was significantly reduced in $7 \mathrm{dpf}$ larvae ( $3 \mathrm{dpf}$ vs. $7 \mathrm{dpf}: p=0.024$; $5 \mathrm{dpf}$ vs. $7 \mathrm{dpf}: p=0.007)$. Furthermore, there was less variability in the average cell speed of GFP+ cells at $7 \mathrm{dpf}$ relative to 3 or $5 \mathrm{dpf}$.

In summary, pax7a+ cells display different cell behaviors at 3 , 5 , and $7 \mathrm{dpf}$, with changes in cell migratory behavior and location.

To confirm that GFP expression in cells of the myotome of pax7a:eGFP larvae occurs in Pax7-expressing cells, we performed immunohistochemistry on 4 and $7 \mathrm{dpf}$ larvae to detect GFP and $\operatorname{Pax} 7$ (Figures 4G-H') and counted the number of labeled cells in the myotome (Figure 4I). This analysis shows that approximately $70 \%$ of Pax7+ cells also express the GFP protein in both 4 and 7 dpf larvae (Figure 4I). Further, we note that approximately $92 \%$ of GFP + cells also express Pax7 at $4 \mathrm{dpf}$, with the remaining $8 \%$ accounting for freshly divided or differentiating cells (data not shown). We are thus confident that the pax7a:eGFP line is an accurate reporter of Pax7 protein expression in the myotome.

\section{pax7a+ Cells Show Differential Responses to Muscle Injury Dependent on Age}

Pax7+ SCs are the principal cell type that regenerates muscle in mammals (Relaix and Zammit, 2012), but it is not clear if this is true for zebrafish. To characterize the response of pax7a+cells to muscle injury in zebrafish, we generated a small single myotome injury in 4 and $7 \mathrm{dpf}$ pax7a:eGFP larvae and observed GFP+ cell responses by time-lapsed recordings from $30 \mathrm{~min}$ after injury (Videos S4, S5).

In pax7a:eGFP larvae injured at $4 \mathrm{dpf}$, the first GFP+ cell responses (extension of processes) were observed as soon as 

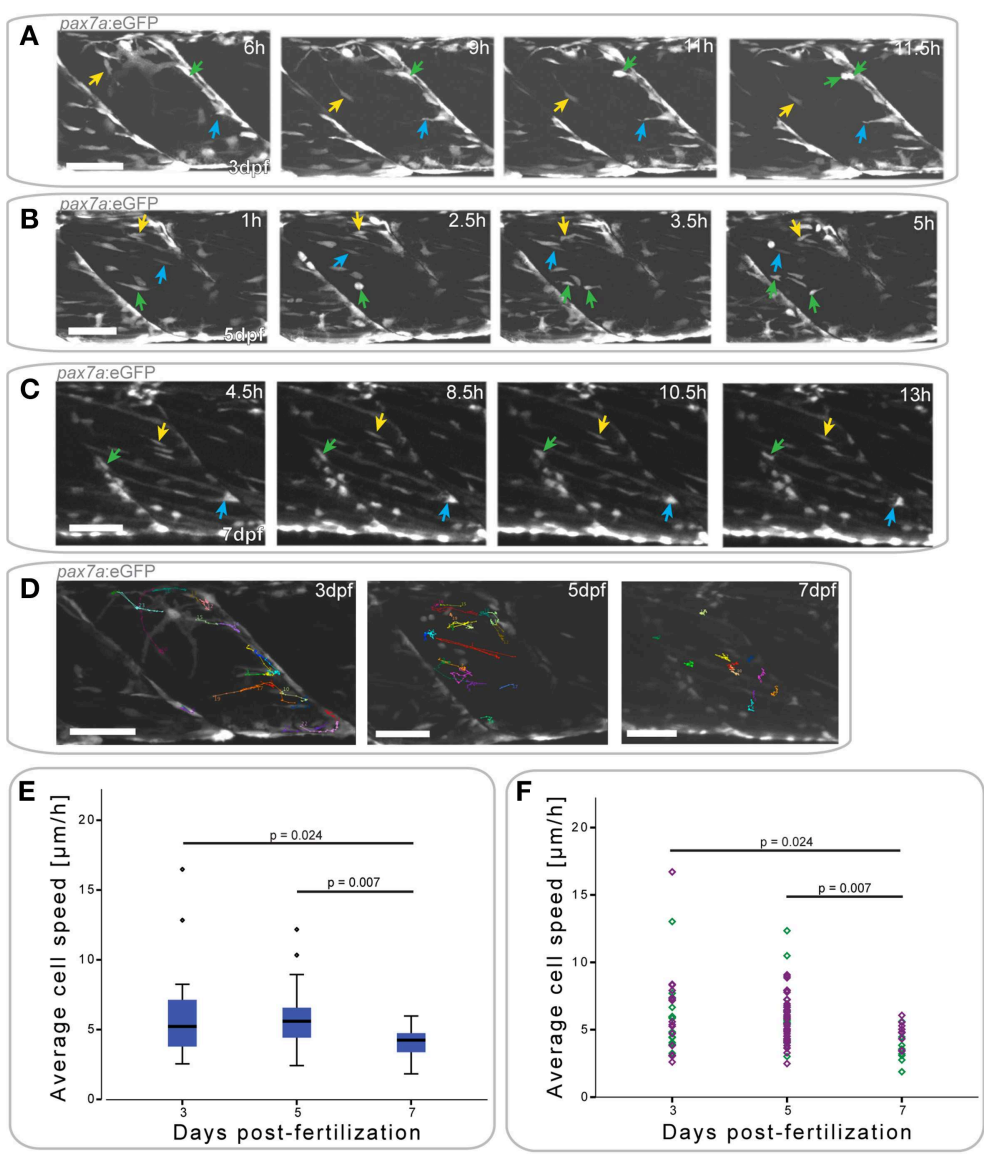

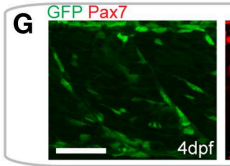

H

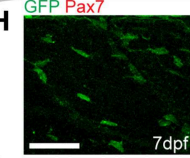

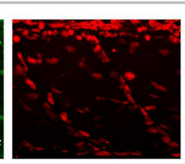

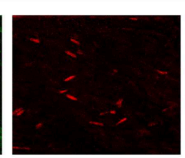

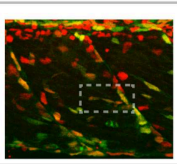

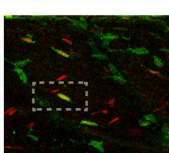

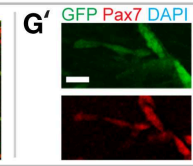

$\mathbf{H}^{\prime}$

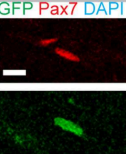

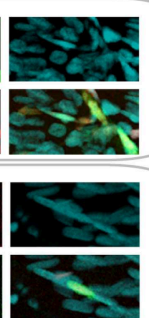

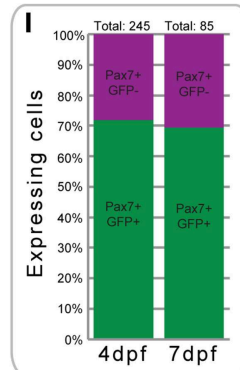

FIGURE 4 | pax7a+ cells in the myotome display changes in their behavior depending on developmental stage. (A) Z-projections of selected time-points captured every $30 \mathrm{~min}$ after the start of a confocal time-lapse stack of an uninjured pax7a:eGFP larva at $3 \mathrm{dpf}$. Arrowheads of different colors indicate cells which show characteristic cell movement throughout the time-lapse. (B,C) Z-projections of selected time-points after the start of a confocal time-lapse stack of an uninjured pax7a:eGFP larva at $5 \mathrm{dpf}$ (B) and $7 \mathrm{dpf}$ (C). Arrowheads of different colors indicate cells which show characteristic cell movement throughout the time-lapse. (D) Z-projections of the last frame of time-lapse recordings shown in (A-C). Individual cells were manually tracked throughout the duration of time-lapse recordings using Fiji MtrackJ. Colored and numbered lines indicate the movement of individual cells through the entire duration of the time-lapse for 3, 5, and 7 dpf larvae. (E) Box plot indicating the average velocity of cells tracked in $n=2$ time-lapse recordings in 3,5 , and $7 \mathrm{dpf}$ larvae. $P$-values were calculated using One-Way ANOVA with Tukey post-hoc test. (F) Scatter plot indicating the average velocity of individual cells in $n=2$ timelapse recordings in 3, 5, and $7 \mathrm{dpf}$ larvae. Each diamond represents one cell; different colors indicate the n-number, thus different individual larvae. $P$-values were calculated using One-Way ANOVA with Tukey post-hoc test. $(\mathbf{G}, \mathbf{H})$ Z-projections of $4 \mathrm{dpf}(\mathbf{G})$ or $7 \mathrm{dpf}$ (H) pax7a:eGFP larvae immunostained for GFP (green) and Pax7 (red). $\left(\mathbf{G}^{\prime}, \mathbf{H}^{\prime}\right)$ Magnified images of boxed region in $\mathbf{( G )}$ or $\mathbf{( H )}$, respectively with addition of DAPI image (cyan) and GFP/Pax7/DAPI merge. Left is anterior, top is dorsal, scale bar is $50 \mu \mathrm{m}$ for images of myotome, $10 \mu \mathrm{m}$ for magnified images. (I) Percentage bar chart indicating the proportion of pax7a-expressing cells which are GFP+ in un-injured $4(n=12)$ and $7 \mathrm{dpf}$ $(n=12)$ larvae.
4 hpi (Figure 5A); cells moved toward the injury from both vertical and horizontal myosepta (Figure $\mathbf{5 A}$, orange and purple arrows). At the site of injury, GFP+ cells then elongated in the same orientation as existing fibers between 9 and $14 \mathrm{hpi}$. GFP+ cells located in the middle of the myotome responded to the injury in the same manner as those at the myosepta, displaying a migratory response to the injury (Figure $\mathbf{5 A}$, turquoise arrow). 


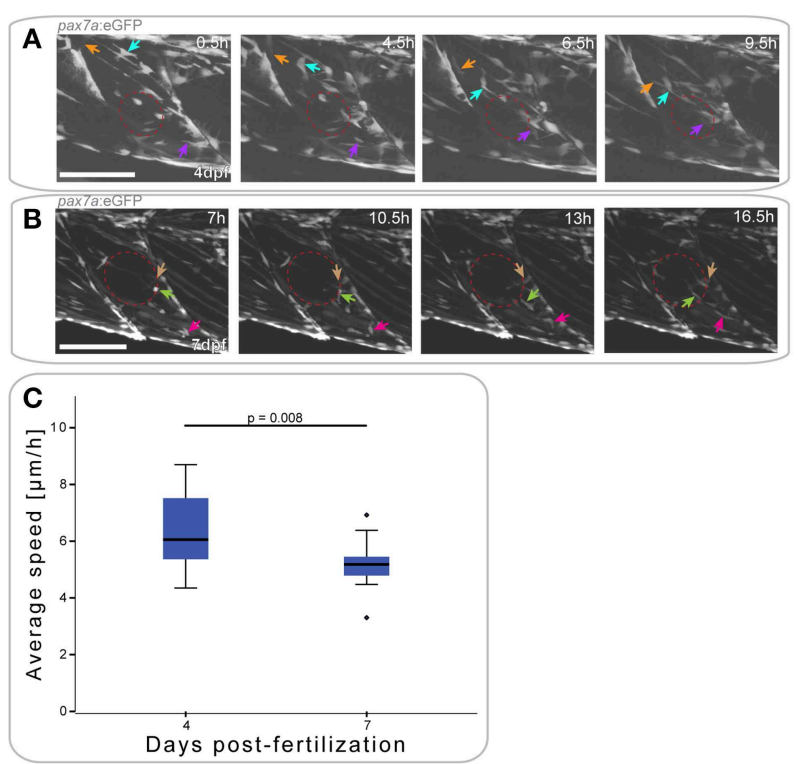

FIGURE 5 | pax7a+ cells show differential responses to muscle injury dependent on age. (A,B) Z-projections of selected time-points after the start of a confocal time-lapse stack of a pax7a:eGFP larva injured at $4 \mathrm{dpf}$ (A) or $7 \mathrm{dpf}$ (B). Recording was started $30 \mathrm{~min}$ after injury and stacks captured every $30 \mathrm{~min}$. Red ellipse indicates the site of injury, arrowheads of different colors indicate cells which show characteristic cell movement throughout the time-lapse. Left is anterior, top is dorsal, scale bar is $100 \mu \mathrm{m}$ for all images. (C) Box plot indicating the average velocity of cells tracked in time-lapse recordings of larvae injured at 4 or $7 \mathrm{dpf}(n=2$ at each stage). $P$-values were calculated using Student's $t$-Test.

Muscle injury in $7 \mathrm{dpf}$ pax7a:eGFP larvae resulted in GFP+ cells extending thin processes toward the injury around $7 \mathrm{hpi}$ (Figure 5B, maroon arrow). Cell movement toward the site of injury was not visible until approximately $10 \mathrm{hpi}$. At this stage, cells adjacent to the injury site (Figure 5B, light green arrow) and at more distal locations (Figure 5B, pink arrow) adopted an elongated morphology.

To determine whether cell responses to injury are affected by developmental stage, we again tracked GFP+ cells. Average cell speed of only those cells that responded to the injury was measured and plotted (Figure 5C). This revealed that GFP+ cells responding to muscle injury in $7 \mathrm{dpf}$ larvae were significantly slower than those in $4 \mathrm{dpf}$ larvae $(p=0.008)$.

\section{pax7a-expressing Cells Do Not Contribute to Fiber Formation after Small Single Myotome Injury}

The response of GFP+ cells to muscle injury in pax7a:eGFP larvae suggests that they may contribute to muscle repair. To test this, we investigated whether GFP+ cells can contribute to myofiber formation after injury, by assessing whether GFP was localized to F-actin+ muscle fibers labeled with fluorophoreconjugated phalloidin.

In pax7a:eGFP larvae with a small single myotome injury at $4 \mathrm{dpf}$, GFP+ cells were clearly localized to the site of injury by 24 hpi (Figures 6A, $\mathbf{A}^{\prime}$ ). Interestingly, these cells were clustered in the gaps between myofibers observed after injury, although many GFP- cells were also present (data not shown). However, no GFP+/F-actin + striated muscle fibers were detected at the injury site, which would be indicative of myofibers derived from cells expressing the pax7a:eGFP transgene. Despite this absence of GFP + F-actin + fibers, GFP + cells could be seen in close proximity to each other and sometimes with multiple DAPI labeled nuclei at $24 \mathrm{hpi}$ (7/9 samples), which may indicate fusion (Figure S1A). GFP + cells were no longer present in clusters by 48 hpi, coincident with loss of the spaces between myofibers. Again, no GFP+/F-actin + muscle fibers were detected at this stage. By 72 hpi, GFP+ cells were found between myofibers, similar to those in uninjured myotomes.

In pax7a:eGFP larvae injured at $7 \mathrm{dpf}$, fewer GFP+ cells were observed at the wound site at $24 \mathrm{hpi}$, relative to those injured at $4 \mathrm{dpf}$. Clusters of GFP + cells could be observed at the wound site at both 24 and 48 hpi when larvae were injured at $7 \mathrm{dpf}$ (Figures 6B, $\mathbf{B}^{\prime}$ ). Similarly to $4 \mathrm{dpf}$ larvae, GFP+ cells lay close to each other and could sometimes be identified as multinuclear (4/5 samples; Figure S1B). At 72 hpi, these GFP+ cells were still present in the deep portions of the myotome, but disappeared in the superficial layers. We were not able to observe GFP+/Factin + fibers at any of these time-points in $7 \mathrm{dpf}$ larvae, similar to our findings from $4 \mathrm{dpf}$ larvae.

We confirmed these findings using GFP/Pax7 coimmunostaining at $24 \mathrm{hpi}$ in larvae injured at 4 or $7 \mathrm{dpf}$ (Figures 6C-D' ${ }^{\prime}$. This shows that many cells that are localized to the site of injury also express the Pax7 protein.

\section{pax7a-expressing Cells Contribute to Fiber Formation after Extensive Single Myotome Injury}

Since we were unable to identify GFP+ muscle fibers in small single myotome injured pax7a:eGFP larvae, we wondered whether the size of injury could influence the ability of pax7a+ cells to contribute to muscle regeneration. We tested this by inducing an extensive single myotome injury in 4 and $7 \mathrm{dpf}$ larvae and evaluated the ability of GFP+ cells to form myofibers at different times after injury.

Following injury of $4 \mathrm{dpf}$ pax7a:eGFP larvae, we observed numerous GFP+ cells around the site of injury at $24 \mathrm{hpi}$ (Figures 7A, $\mathbf{A}^{\prime}$ ). Elongated GFP+ cells were first observed at $48 \mathrm{hpi}$, and GFP+/F-actin+ fibers were first observed at 72 hpi (Figure $\mathbf{7 \mathbf { A } ^ { \prime }}$ ). Interestingly, we noted that some of the regenerating fibers in the injured myotome were not GFP+ (Figure 7A, see 72 hpi arrow). GFP+ cells were still present within the injured myotome at $144 \mathrm{hpi}$, but were less numerous than at earlier stages of injury.

A similar response of GFP + cells was observed in pax7a:eGFP larvae injured extensively at $7 \mathrm{dpf}$ (Figure 7B). GFP+ cells were present in the injured myotome at 24 and $48 \mathrm{hpi}$ and seemed to lie in the same orientation as existing muscle fibers (Figure $\mathbf{7} \mathbf{B}^{\prime}$ ). The first GFP+/F-actin+ fibers appeared by $72 \mathrm{hpi}$ and were detectable until 120 hpi in the injured myotome. By $144 \mathrm{hpi}$, GFP+ cells were still present within the myotome, though GFP+ fibers could no longer be observed (Figure 7B).

Again, we confirmed the presence of Pax7-expressing cells at the site of injury at $48 \mathrm{hpi}$ using GFP/Pax7 

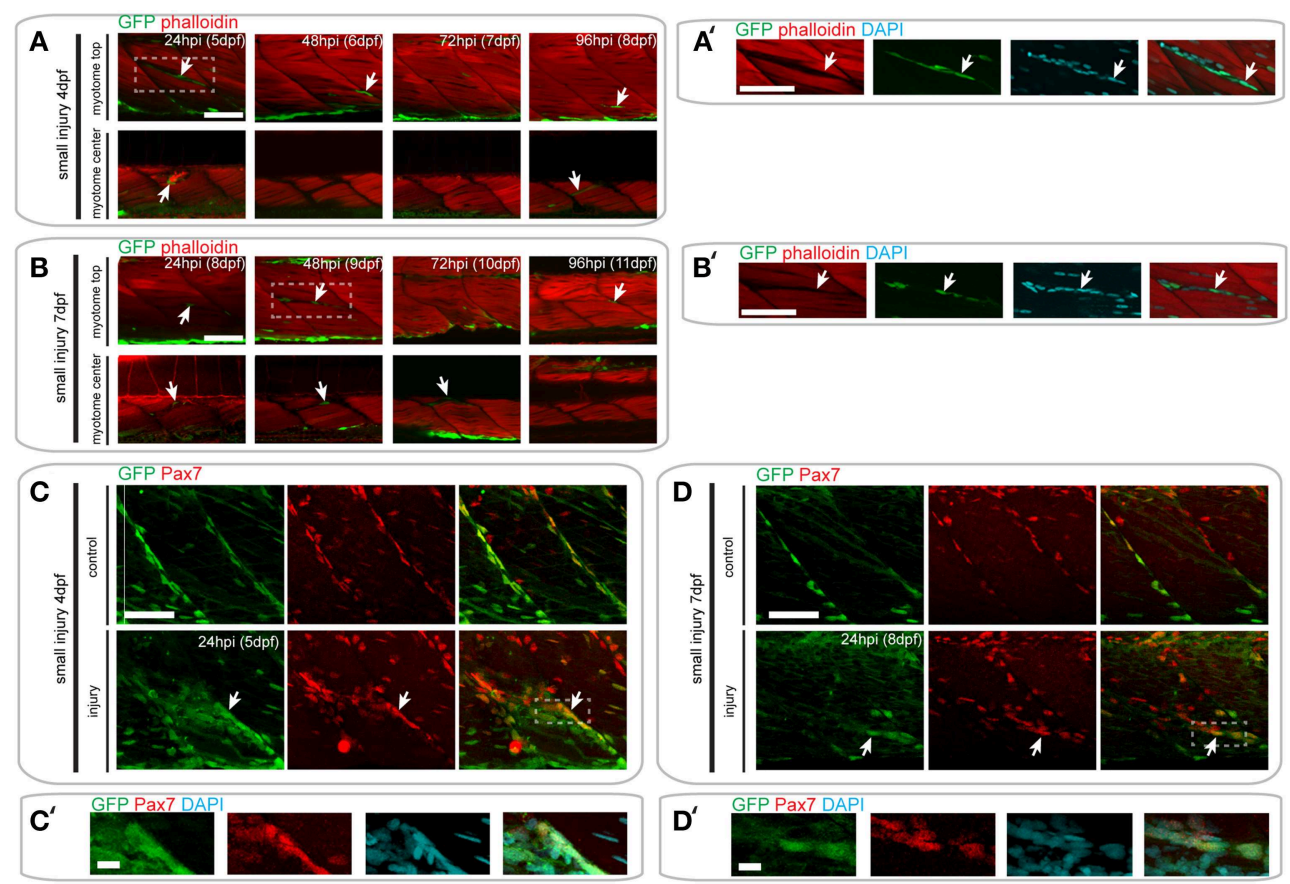

FIGURE 6 | Pax7a-expressing cells do not contribute to muscle fiber formation after small single myotome injury. (A,B) Confocal slices of the superficial and deep 12th ventral myotome of pax7a:eGFP larvae injured at $4 \mathrm{dpf}$ (A) or $7 \mathrm{dpf}$ (B) and stained for phalloidin ( $\mathrm{f}$-actin, red) and GFP (green) after small single myotome injury. Arrowheads indicate cells of interest. ( $\left(\mathbf{A}^{\prime}, \mathbf{B}^{\prime}\right)$ Magnified images of boxed regions in $(\mathbf{A})$ or $(\mathbf{B})$, respectively. Images show staining for phalloidin (f-actin, red), GFP (green) and DAPI (cyan). Arrowheads indicate cells of interest. (C,D) Z-projections of $4 \mathrm{dpf}$ (C) or $7 \mathrm{dpf}$ (D) pax7a:eGFP larva immunostained for GFP (green) and Pax7 (red) at 24 hpi after small single myotome injury. $\left(\mathbf{C}^{\prime}, \mathbf{D}^{\prime}\right)$ Magnified images of boxed region in (C) or (D), respectively with addition of DAPI image (cyan) and GFP/Pax7/DAPI merge. Scale bar is $10 \mu \mathrm{m}$. For all other images, scale bars are $50 \mu \mathrm{m}$. Left is anterior, top is dorsal. immunohistochemistry (Figures $7 \mathrm{C}-\mathrm{D}^{\prime}$ ). This staining shows that there is a large number of Pax7-expressing cells present at the site of injury in larvae injured at 4 and $7 \mathrm{dpf}$. Many of these cells also expressed GFP, indicating that the pax $7 a+$ cells contributing to regeneration are expressing Pax7 protein.

\section{A Pool of pax7a-expressing Cells is Recruited for Repair and Regeneration in 7 dpf, but Not 4 dpf Animals}

To assess whether pax $7 a$-expressing cells proliferated in response to injury, similar to mammals, we pulsed pax7a:eGFP larvae after injury with BrdU and counted GFP+ and BrdU+ cells after immunostaining.

At $24 \mathrm{~h}$ after creation of a small single myotome injury in 4 and $7 \mathrm{dpf}$ pax7a:eGFP larvae, there was clearly observable cell proliferation (Figures $\mathbf{8 A}, \mathbf{B}$ ). Upon injury, the number of $\mathrm{GFP}+\mathrm{BrdU}+$ cells increased 0.7 -fold in $4 \mathrm{dpf}$ larvae, whereas the number of GFP + BrdU- cells did not obviously change. In $7 \mathrm{dpf}$ larvae we observed a significant increase in the number of proliferating GFP + cells after injury $(p=0.006)$, which was coincident with a sharp decrease in the number of BrdU- cells $(p<0.001)$.

Similar trends can be observed $48 \mathrm{~h}$ after extensive single myotome injury (Figures 8C,D). In pax7a:eGFP larvae injured at $4 \mathrm{dpf}$, there was a significant increase in the number of proliferating GFP+ cells compared to controls $(p=0.003)$. We also observed a slight increase in the number of GFP+BrdUcells at this stage. In $7 \mathrm{dpf}$ larvae, the increase in the number of proliferating GFP+ cells was even more pronounced than for small single myotome injuries $(p<0.001)$. Further, we observed the same reduction in number of GFP + BrdU- cells as seen occurring after small injuries $(p<0.001)$.

When comparing the average number of counted cells in 4 and $7 \mathrm{dpf}$ pax7a:eGFP larvae, it is notable that there were consistently more GFP+BrdU+ cells present in $4 \mathrm{dpf}$ larvae compared to $7 \mathrm{dpf}$. Of further interest, we found that most GFP+ cells were proliferative at $4 \mathrm{dpf}$ in uninjured larvae, whereas no GFP+ cells showed BrdU incorporation in uninjured $7 \mathrm{dpf}$ larvae.

Thus, we observe significant differences in the proliferation patterns of GFP+ cells in response to small and extensive single myotome injury between 4 and $7 \mathrm{dpf}$ pax7a:eGFP larvae.

\section{Discussion}

Skeletal muscle regeneration is a complex process, involving the activation and differentiation of stem cells and their integration into existing muscle tissue or formation of de novo myofibers. In this study, we characterize the response of a population of muscle-resident pax7a+ cells during muscle injury and repair in zebrafish. We describe two reproducible mechanical injury 

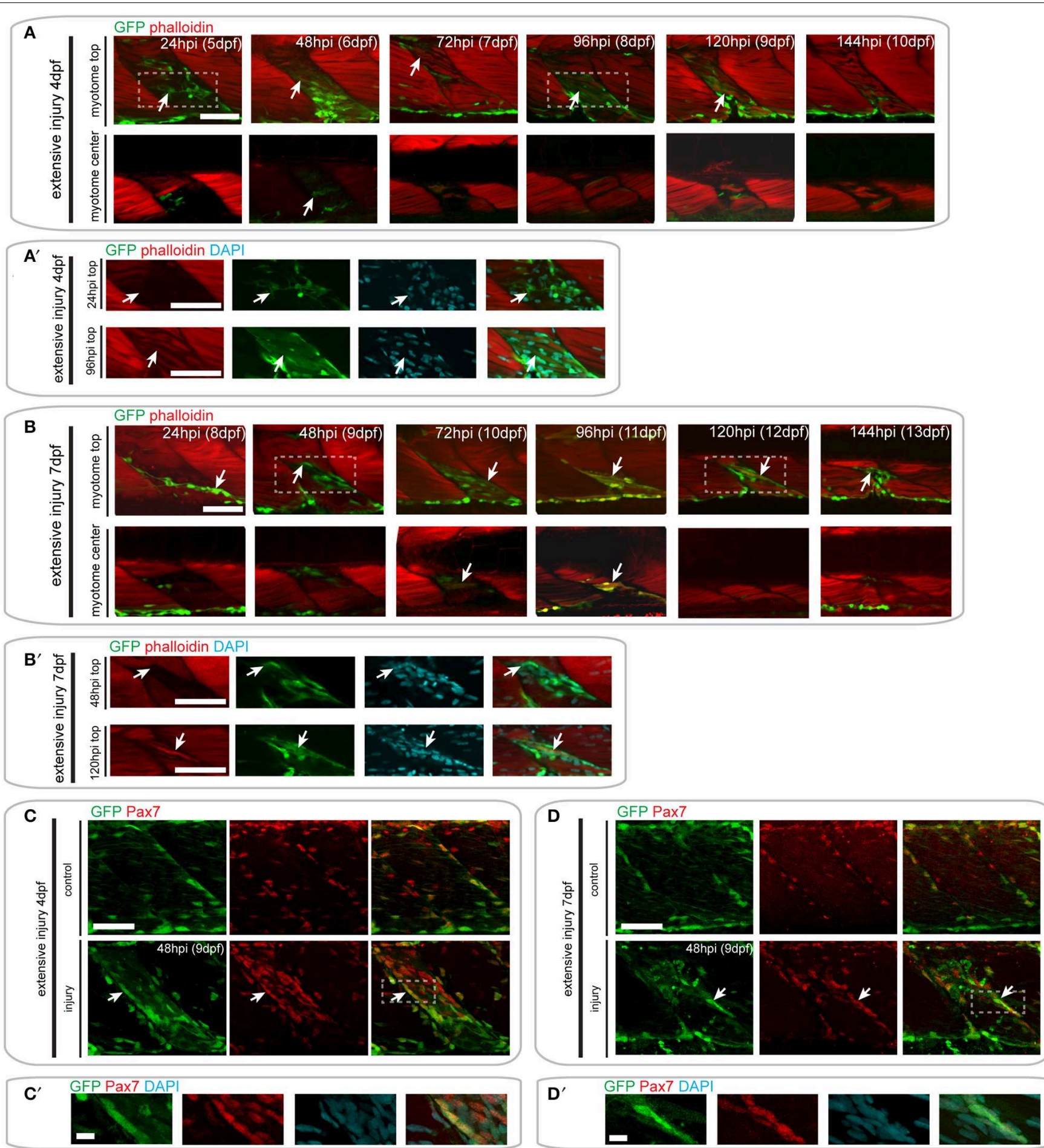

FIGURE 7 | Pax7a-expressing cells contribute to muscle fiber formation after extensive single myotome injury. (A,B) Confocal slices of the superficial and deep 12th ventral myotome of pax7a:eGFP larvae injured extensively at $4 \mathrm{dpf}$ (A) or $7 \mathrm{dpf}$ (B) and stained for phalloidin (f-actin, red) and GFP (green) after injury. Arrowheads indicate cells of interest and regenerating GFP-positive fibers. $\left(\mathbf{A}^{\prime}, \mathbf{B}^{\prime}\right)$ Magnified images of boxed regions in $(\mathbf{A})$ or $(\mathbf{B})$, respectively. Images show staining for phalloidin (f-actin, red), GFP (green) and DAPI (cyan). Arrowheads indicate cells of interest. (C,D) Z-projections of $4 \mathrm{dpf}$ (C) or $7 \mathrm{dpf}$ (D) pax7a:eGFP larvae immunostained for GFP (green) and Pax7 (red) at 48 hpi after extensive single myotome injury. ( ( $\left.\mathbf{C}^{\prime}, \mathbf{D}^{\prime}\right)$ Magnified images of boxed region in (C) or (D), respectively with addition of DAPI image (cyan) and GFP/Pax7/DAPI merge. Scale bars are $10 \mu \mathrm{m}$. For all other images, scale bars are $50 \mu \mathrm{m}$. Left is anterior, top is dorsal. 


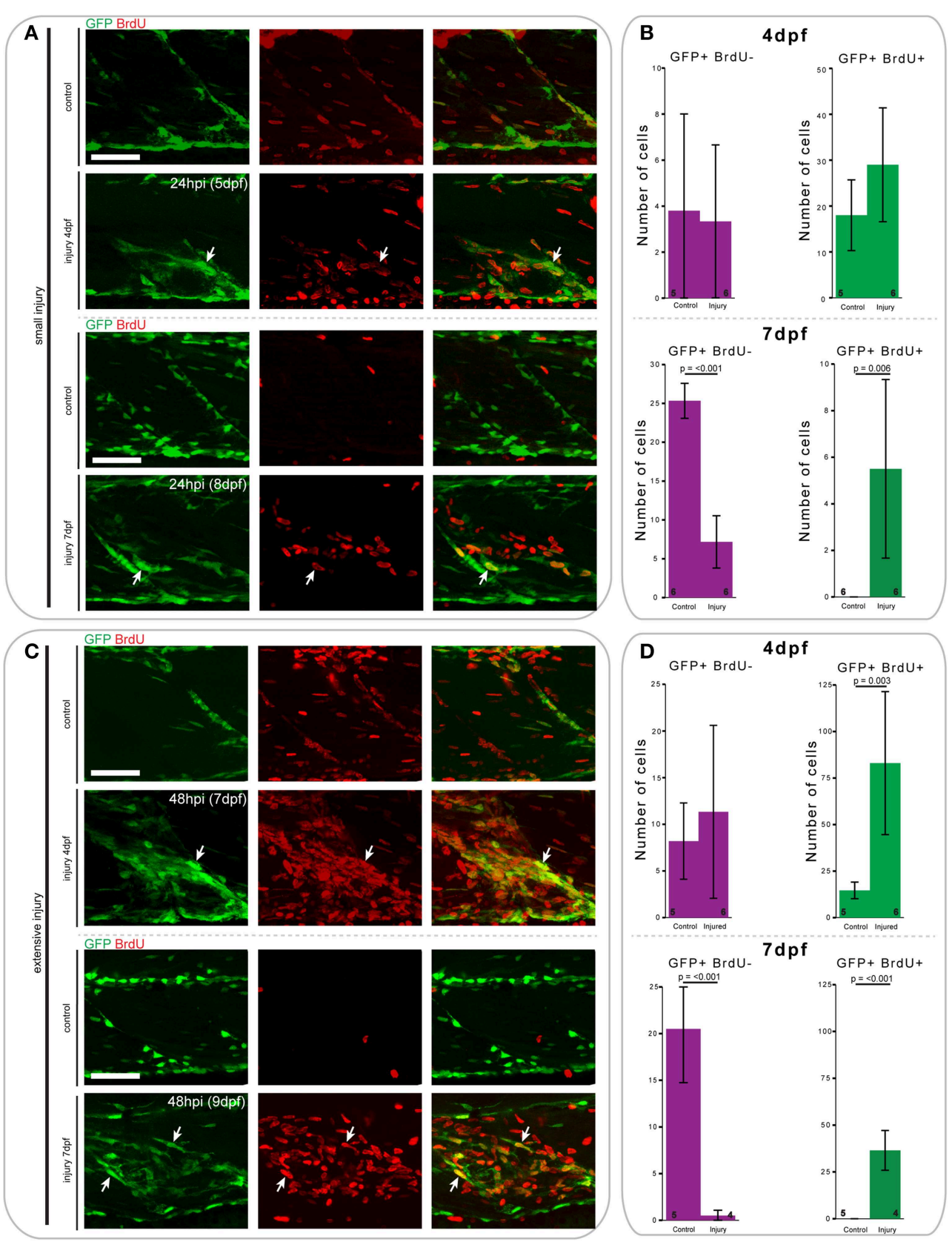

FIGURE 8 | Proliferation patterns of pax7a-expressing cells differ between 4 and $7 \mathrm{dpf}$ larvae following small and extensive single myotome injury. (A,C) Z-projections of 4 and $7 \mathrm{dpf}$ pax7a:eGFP larva immunostained for GFP (green) and BrdU (red) at 24 hpi after small (A) or extensive (C) single myotome injury. Larvae were incubated in $10 \mathrm{mM}$ BrdU/1\% DMSO during the entirety of the recovery period. Arrows indicate cells which show double staining. Scale bars are $50 \mu \mathrm{m}$. Left is anterior, top is dorsal. (B,D) Bar charts indicating the average number of GFP+BrdU- or GFP+BrdU+ cells after small (B) or extensive (D) single myotome injury compared to un-injured controls. Single cells were counted at $24 \mathrm{hpi}$ (B) or $48 \mathrm{hpi}$ (D) in larvae injured at 4 or $7 \mathrm{dpf}$. Numbers of larvae counted are indicated in small font at the bottom of each bar. models, resulting in minor or extensive damage to muscle fibers. We show these injuries are repaired and involve the expression of MRF genes, as seen in other vertebrates. Such injuries elicit the response of a population of pax $7 a$-expressing cells resident in the myotome, which migrate to sites of muscle injury in a transgenic pax7a:eGFP line. The contribution of pax7aexpressing $(\mathrm{GFP}+)$ cells to regenerating muscle was dependent on the injury extent: they contributed to fiber formation after extensive single myotome injury, whereas a small injury did not lead to participation of pax7a-expressing (GFP+) cells in fiber 
repair. We also found that developmental stage was important for the speed of these cells and the duration of MRF expression in the regenerative phase. Overall, this highlights the diverse response of a muscle-resident pax7a-expressing cell population to injury and suggests that their role during regeneration can be affected by several parameters.

\section{Variations in Injury Size Might Alter muSC Behavior during Regeneration}

Little is known about the behavior of muscle progenitor cells during the regeneration of skeletal muscle in zebrafish. In larval muscle, it has been shown that Pax3/Pax7-expressing cells are proliferative and accumulate around the site of injury (Seger et al., 2011). We observe that pax7a+ cells migrate toward the wound site through the extension of cytoplasmic processes, though we do not see evidence of proliferation using timelapsed imaging. This mode of migration may in part be regulated by Rho/Rac GTPases (Murali and Rajalingam, 2014). On the contrary, in an in vitro single fiber system, mammalian SCs have been described to migrate through blebbing (Otto et al., 2011). This process also appears to be dependent on Rho kinase (ROCK) function, as application of small molecule inhibitors caused cells to display a slower movement (Collins-Hooper et al., 2012). Although we cannot clearly discriminate between a mesenchymal or amoeboid cell movement, we note that migrating pax7aexpressing cells in vivo clearly extend cytoplasmic processes.

Initially, we hypothesized that pax7a-expressing cells in injured larvae would contribute to tissue regeneration, as seen in mammals. However, we were unable to verify any contribution of GFP + cells to fiber formation after small injury in pax7a:eGFP larvae. An earlier study, in which a different pax7a:GFP line was used, likewise did not show a contribution of GFP+ cells to regenerating fibers following cardiotoxin injection (Seger et al., 2011). Despite this, MRFs are expressed in response to small single myotome injury and GFP+ cells proliferate and migrate to the site of injury. Further, the presence of multi-nuclear and closely associated GFP + cells is strongly indicative that fusion occurs in our small injury model. Perhaps, the number of pax7aexpressing cells contributing to repair in this injury model is not extensive, preventing detection of residual GFP protein in newly regenerated fibers. Alternatively, other cell populations may play a more prominent role in the context of small injuries. For instance, zebrafish also possess a paralog of the pax7a gene, named pax7b. The Pax7 antibody used in this study is unable to distinguish between these two Pax7 isoforms. Examination of fish models with a reporter gene targeted to the pax $7 b$ locus would be useful to determine the contribution of this isoform to muscle repair in the context of small injuries.

In mouse, Pax7+ cells are crucial for muscle to sustain its regenerative ability (Relaix and Zammit, 2012). Many muscleresident cell populations, which do not express Pax7, have previously been shown to be able to contribute to muscle regeneration, such as side-population cells (Gussoni et al., 1999; Asakura et al., 2002), muscle-derived stem cells (Qu-Petersen et al., 2002) and CD133+ progenitor cells (Torrente et al., 2004). Even though these particular cell populations have not been described in zebrafish, it is possible that such a non-pax7expressing cell population acts to repair small injuries to the muscle tissue, whereas pax7a-expressing cells only regenerate muscle following larger insult.

In vitro data from a related species of cyprinid, Devario aequipinnatus or giant Danio, shows that Pax7 is actually only expressed in newly activated muSCs, whereas Pax3 is present throughout myoblast proliferation (Froehlich et al., 2013). It is thus possible that pax3-expressing cells or other myogenic progenitor cells in fish might actually resemble a mammalian muSC population more closely than the cells we observed in our work. Considering our rudimentary understanding of sub-populations of muSCs and their roles in regeneration, especially in humans (Boldrin et al., 2010), studying these in zebrafish might lead to new insights other animal models cannot provide. We have not examined the role of pax3expressing cells during muscle regeneration in zebrafish, though it is well-established that $\operatorname{Pax} 3$ acts to specify early muscle progenitor cells in mouse (Schubert et al., 2001). Given that Pax3 and Pax7 are related transcription factors that are both important for specifying muscle progenitor cell populations, it is possible that $\operatorname{Pax} 3$ may also be important for regeneration in zebrafish.

Proteins of the muscle extra-cellular matrix, such as the dystrophin-associated protein complex and laminins, are localized at the myosepta in zebrafish (Gupta et al., 2012; Wood and Currie, 2014). In accordance with prior findings (Seger et al., 2011), we note that the pax7a-expressing cells in the myotome of larval fish are localized to the myosepta, suggesting it is an environment that maintains this cell population. Given that we observe many pax7a-expressing cells with low levels of division by $7 \mathrm{dpf}$, it is tempting to speculate the myoseptum may act as a niche for these cells. Our extensive single myotome injury paradigm may indeed perturb the myoseptum, which could explain the differential regeneration response we see with respect to injury size. In this context, it is conceivable that signals from the myoseptum dictate the response of pax7a-expressing cells to injury.

\section{Variations in Age Might Alter muSC Behavior during Regeneration}

The difference in the dynamics of regeneration between larvae injured at 4 and $7 \mathrm{dpf}$ is very consistent. Most interestingly, $\mathrm{GFP}+$ cells in pax7a:eGFP larvae migrate toward the injury significantly slower when injured at $7 \mathrm{dpf}$ compared to $4 \mathrm{dpf}$. In vitro studies of SCs isolated from mouse have previously shown that older cells show slower migration along myofibers (Collins-Hooper et al., 2012). The amount of GFP+ cells that proliferate in response to injury is also consistently lower in $7 \mathrm{dpf}$ larvae compared to $4 \mathrm{dpf}$ larvae. Further, we observe prolonged expression of MRFs and fewer regenerative fibers in larvae injured at $7 \mathrm{dpf}$ relative to $4 \mathrm{dpf}$. These observations suggest that the cell populations contributing to muscle regeneration in older animals are less efficient or slower in their responses. It is possible that pax7a-expressing cells at $4 \mathrm{dpf}$ may be more developmentally plastic or poised, thus more prone to respond to stimuli than at later stages. This phenomenon might 
well-reflect the entry of pax7a-expressing cells into quiescence after the completion of developmental myogenesis. This is also supported by our observation that we did not observe GFP+ cells undergoing proliferation in uninjured $7 \mathrm{dpf}$ pax7a:eGFP animals, whereas there is ample proliferation in uninjured $4 \mathrm{dpf}$ control fish.

It has been suggested that stem cell quiescence may be caused by the accumulation of histone marks, which promote the formation of heterochromatin, thus inhibiting gene expression (Grigoryev et al., 2004; Srivastava et al., 2010). Furthermore, the chromatin of muSCs shows an increased deposition of inhibitory histone marks during aging, which may correlate with impaired muSC function in regeneration (Liu et al., 2013). It is possible that similar mechanisms of epigenetic gene inactivation lead to decreased muSC activity between 4 and $7 \mathrm{dpf}$, explaining the difference in cell speed and regenerative responses.

Alternatively, the changes in cell behavior we observed may reflect an alteration of the environment of muSCs, such as changes to the ECM. Indeed, significant changes occur to the ECM between 3 and 6 dpf larvae (Charvet et al., 2011). Most notably, collagen organization changes from a loose, disorganized meshwork into a dense, regular network of collagen fibrils. Since it is well-known that the cellular environment of SCs can greatly impact their behavior (Montarras et al., 2013), it is conceivable that this maturation of the ECM in the myotome may lead to changes in pax7a-expressing cell response to injury and thus affects the speed of tissue regeneration.

\section{Conclusion}

Our finding that responses of pax7a-expressing cells are dictated by the extent of the muscle injury are intriguing, especially since most injury models in mouse, such as cardiotoxin injection or crush injuries, result in a severe disruption of the tissue, leading to extensive regeneration. The impact of age on the behavior of muSCs in zebrafish and their efficiency in regenerating muscle also provides a new consideration for the study of muSC plasticity.

\section{References}

Akster, H. A. (1983). A comparative study of fiber type characteristics and terminal innervation in head and axial muscle of carp (Cyprinus carpio L.) A histochemical and electron-microscopical study. Neth. J. Zool. 33, 164-188. doi: $10.1163 / 002829683$ X00075

Alexander, M. S., Kawahara, G., Kho, A. T., Howell, M. H., Pusack, T. J., Myers, J. A., et al. (2011). Isolation and transcriptome analysis of adult zebrafish cells enriched for skeletal muscle progenitors. Muscle Nerve 43, 741-750. doi: 10.1002/mus.21972

Asakura, A., Seale, P., Girgis-Gabardo, A., and Rudnicki, M. A. (2002). Myogenic specification of side population cells in skeletal muscle. J. Cell Biol. 159, 123-134. doi: $10.1083 /$ jcb. 200202092

Boldrin, L., Muntoni, F., and Morgan, J. E. (2010). Are human and mouse satellite cells really the same? J. Histochem. Cytochem. 58, 941-955. doi: 10.1369/jhc. 2010.956201

Charvet, B., Malbouyres, M., Pagnon-Minot, A., Ruggiero, F., and Le Guellec, D. (2011). Development of the zebrafish myoseptum with emphasis on the

\section{Acknowledgments}

SK was funded by a King's College London Dental Institute studentship. RK is supported by grants from the Wellcome Trust and BBSRC. PZ is supported by the Medical Research Council, Association Française contre les Myopathies, Muscular Dystrophy UK, FSHSoc, and the EU FP7 network BIODESIGN. We thank Simon Hughes, Shukolpa Dutta Roy and Yaniv Hinits for discussions and help with experimental procedures and Sören Alsheimer and Christiane Nüsslein-Volhard for the pax7a:eGFP transgenic fish line prior to publication.

\section{Supplementary Material}

The Supplementary Material for this article can be found online at: http://journal.frontiersin.org/article/10.3389/fnagi. 2015.00161

Video S1 | Z-projection of a confocal time-lapse stack of an uninjured pax7a:eGFP larva at $\mathbf{3}$ dpf. Stacks were captured every $30 \mathrm{~min}$ in $1 \mu \mathrm{m}$ slices from skin to neural tube. Left is anterior, top is dorsal.

Video S2 | Z-projection of a confocal time-lapse stack of an uninjured pax7a:eGFP larva at $\mathbf{5} \mathbf{d p f}$. Stacks were captured every $30 \mathrm{~min}$ in $1 \mu \mathrm{m}$ slices from skin to neural tube. Left is anterior, top is dorsal.

Video S3 | Z-projection of a confocal time-lapse stack of an uninjured pax7a:eGFP larva at $\mathbf{7}$ dpf. Stacks were captured every $30 \mathrm{~min}$ in $1 \mu \mathrm{m}$ slices from skin to neural tube. Left is anterior, top is dorsal.

Video S4 | Z-projection of a confocal time-lapse stack of pax7a:eGFP larva injured at $\mathbf{4}$ dpf. Capture was started 30 min after injury and stacks were captured every $30 \mathrm{~min}$ in $1 \mu \mathrm{m}$ slices from skin to neural tube. Left is anterior, top is dorsal.

Video S5 | Z-projection of a confocal time-lapse stack of pax7a:eGFP larva injured at $\mathbf{7}$ dpf. Capture was started 30 min after injury and stacks were captured every $30 \mathrm{~min}$ in $1 \mu \mathrm{m}$ slices from skin to neural tube. Left is anterior, top is dorsal.

Figure S1 | (A,B) Confocal slices of the 12th ventral myotome of pax7a:eGFP larvae injured at $4 \mathrm{dpf}(\mathrm{A})$ or $7 \mathrm{dpf}(\mathrm{B})$ and stained for phalloidin (f-actin, red), GFP (green), and DAPI (cyan) $24 \mathrm{~h}$ after small injury. Arrowheads indicate cells of interest, which appear to be multinuclear. Scale bars are $25 \mu \mathrm{m}$. Left is anterior, top is dorsal.

myotendinous junction. Cell Tissue Res. 346, 439-449. doi: 10.1007/s00441-0111266-7

Chen, C., Wang, L., Plikus, M. V., Jiang, T. X., Murray, P. J., Ramos, R., et al. (2015). Organ-level quorum sensing directs regeneration in hair stem cell populations. Cell 161, 277-290. doi: 10.1016/j.cell. 2015.02.016

Collins-Hooper, H., Woolley, T. E., Dyson, L., Patel, A., Potter, P., Baker, R. E., et al. (2012). Age-related changes in speed and mechanism of adult skeletal muscle stem cell migration. Stem Cells 30, 1182-1195. doi: 10.1002/ stem. 1088

Conboy, M. J., Karasov, A. O., and Rando, T. A. (2007). High incidence of non-random template strand segregation and asymmetric fate determination in dividing stem cells and their progeny. PLoS Biol. 5:e102. doi: 10.1371/journal.pbio.0050102

Devoto, S. H., Stoiber, W., Hammond, C. L., Steinbacher, P., Haslett, J. R., Barresi, M. J., et al. (2006). Generality of vertebrate developmental patterns: evidence for a dermomyotome in fish. Evol. Dev. 8, 101-110. doi: 10.1111/j.1525142X.2006.05079.x 
Froehlich, J. M., Galt, N. J., Charging, M. J., Meyer, B. M., and Biga, P. R. (2013). In vitro indeterminate teleost myogenesis appears to be dependent on Pax3. In Vitro Cell. Dev. Biol. Anim. 49, 371-385. doi: 10.1007/s11626-013-9616-2

Grigoryev, S. A., Nikitina, T., Pehrson, J. R., Singh, P. B., and Woodcock, C. L. (2004). Dynamic relocation of epigenetic chromatin markers reveals an active role of constitutive heterochromatin in the transition from proliferation to quiescence. J. Cell Sci. 117, 6153-6162. doi: 10.1242/cs.01537

Gros, J., Manceau, M., Thomé, V., and Marcelle, C. (2005). A common somitic origin for embryonic muscle progenitors and satellite cells. Nature 435, 954-958. doi: 10.1038/nature03572

Groves, J. A., Hammond, C. L., and Hughes, S. M. (2005). Fgf8 drives myogenic progression of a novel lateral fast muscle fibre population in zebrafish. Development 132, 4211-4222. doi: 10.1242/dev.01958

Günther, S., Kim, J., Kostin, S., Lepper, C., Fan, C. M., and Braun, T. (2013). Myf5-positive satellite cells contribute to Pax7-dependent long-term maintenance of adult muscle stem cells. Cell Stem Cell 13, 590-601. doi: 10.1016/j.stem.2013.07.016

Gupta, V. A., Kawahara, G., Myers, J. A., Chen, A. T., Hall, T. E., Manzini, M. C., et al. (2012). A splice site mutation in laminin-alpha2 results in a severe muscular dystrophy and growth abnormalities in zebrafish. PLoS ONE 7:e43794. doi: 10.1371/journal.pone.0043794

Gussoni, E., Soneoka, Y., Strickland, C. D., Buzney, E. A., Khan, M. K., Flint, A. F., et al. (1999). Dystrophin expression in the mdx mouse restored by stem cell transplantation. Nature 401, 390-394. doi: 10.1038/43919

Hollway, G. E., Bryson-Richardson, R. J., Berger, S., Cole, N. J., Hall, T. E., and Currie, P. D. (2007). Whole-somite rotation generates muscle progenitor cell compartments in the developing zebrafish embryo. Dev. Cell 12, 207-219. doi: 10.1016/j.devcel.2007.01.001

Kassar-Duchossoy, L., Gayraud-Morel, B., Gomès, D., Rocancourt, D., Buckingham, M., Shinin, V., et al. (2004). Mrf4 determines skeletal muscle identity in Myf5:Myod double-mutant mice. Nature 431, 466-471. doi: 10.1038/nature02876

Koumans, J. T., Akster, H. A., Dulos, G. J., and Osse, J. W. (1990). Myosatellite cells of $\mathrm{C}$ carpio in vitro-isolation recognition and differentiation. Cell Tissue Res. 261, 173-181. doi: 10.1007/BF00329450

Lepper, C., Partridge, T. A., and Fan, C. M. (2011). An absolute requirement for Pax7-positive satellite cells in acute injury-induced skeletal muscle regeneration. Development 138, 3639-3646. doi: 10.1242/dev.067595

Liu, L., Cheung, T. H., Charville, G. W., Hurgo, B. M., Leavitt, T., Shih, J., et al. (2013). Chromatin modifications as determinants of muscle stem cell quiescence and chronological aging. Cell Rep. 4, 189-204. doi: 10.1016/j.celrep.2013.05.043

Maderspacher, F., and Nüsslein-Volhard, C. (2003). Formation of the adult pigment pattern in zebrafish requires leopard and obelix dependent cell interactions. Development 130, 3447-3457. doi: 10.1242/ dev.00519

Mahalwar, P., Walderich, B., Singh, A. P., and Nusslein-Volhard, C. (2014). Local reorganization of xanthophores fine-tunes and colors the striped pattern of zebrafish. Science 345, 1362-1364. doi: 10.1126/science.1254837

Marschallinger, J., Obermayer, A., Sänger, A. M., Stoiber, W., and Steinbacher, P. (2009). Postembryonic fast muscle growth of teleost fish depends upon a nonuniformly distributed population of mitotically active Pax7+ precursor cells. Dev. Dyn. 238, 2442-2448. doi: 10.1002/dvdy.22049

Mauro, A. (1961). Satellite cell of skeletal muscle fibers. J. Biophys. Biochem. Cytol. 9, 493-495. doi: 10.1083/jcb.9.2.493

Montarras, D., L'honoré, A., and Buckingham, M. (2013). Lying low but ready for action: the quiescent muscle satellite cell. FEBS J. 280, 4036-4050. doi: $10.1111 /$ febs. 12372

Moss, F. P., and Leblond, C. P. (1970). Nature of dividing nuclei in skeletal muscle of growing rats. J. Cell Biol. 44, 459-462. doi: 10.1083/jcb.44.2.459

Murali, A., and Rajalingam, K. (2014). Small Rho GTPases in the control of cell shape and mobility. Cell. Mol. Life Sci. 71, 1703-1721. doi: 10.1007/s00018-0131519-6

Nag, A. C., and Nursall, J. R. (1972). Histogenesis of white and red muscle fibres of trunk muscle of a fish Salmo gairdneri. Cytobios 6, 227-246.

Odenthal, J., Rossnagel, K., Haffter, P., Kelsh, R. N., Vogelsang, E., Brand, M., et al. (1996). Mutations affecting xanthophore pigmentation in the zebrafish, Danio rerio. Development 123, 391-398.
Otten, C., van der Ven, P. F., Lewrenz, I., Paul, S., Steinhagen, A., Busch-Nentwich, E., et al. (2012). Xirp proteins mark injured skeletal muscle in zebrafish. PLoS ONE 7:e31041. doi: 10.1371/journal.pone.0031041

Otto, A., Collins-Hooper, H., Patel, A., Dash, P. R., and Patel, K. (2011). Adult skeletal muscle stem cell migration is mediated by a blebbing/amoeboid mechanism. Rejuvenation Res. 14, 249-260. doi: 10.1089/rej.2010.1151

Parichy, D. M., Ransom, D. G., Paw, B., Zon, L. I., and Johnson, S. L. (2000). An orthologue of the kit-related gene fms is required for development of neural crest-derived xanthophores and a subpopulation of adult melanocytes in the zebrafish, Danio rerio. Development 127, 3031-3044.

Qu-Petersen, Z., Deasy, B., Jankowski, R., Ikezawa, M., Cummins, J., Pruchnic, R., et al. (2002). Identification of a novel population of muscle stem cells in mice: potential for muscle regeneration. J. Cell Biol. 157, 851-864. doi: $10.1083 /$ jcb. 200108150

Relaix, F., Rocancourt, D., Mansouri, A., and Buckingham, M. (2005). A Pax3/Pax7-dependent population of skeletal muscle progenitor cells. Nature 435, 948-953. doi: 10.1038/nature03594

Relaix, F., and Zammit, P. S. (2012). Satellite cells are essential for skeletal muscle regeneration: the cell on the edge returns centre stage. Development 139, 2845-2856. doi: $10.1242 / \mathrm{dev} .069088$

Rodrigues, A. M., Christen, B., Martí, M., and Izpisúa Belmonte, J. C. (2012). Skeletal muscle regeneration in Xenopus tadpoles and zebrafish larvae. $B M C$ Dev. Biol. 12:9. doi: 10.1186/1471-213X-12-9

Rowlerson, A., Radaelli, G., Mascarello, F., and Veggetti, A. (1997). Regeneration of skeletal muscle in two teleost fish: sparus aurata and Brachydanio rerio. Cell Tissue Res. 289, 311-322. doi: 10.1007/s004410 050878

Sambasivan, R., Yao, R., Kissenpfennig, A., Van Wittenberghe, L., Paldi, A., Gayraud-Morel, B., et al. (2011). Pax7-expressing satellite cells are indispensable for adult skeletal muscle regeneration. Development 138, 3647-3656. doi: 10.1242/dev.067587

Schindelin, J., Arganda-Carreras, I., Frise, E., Kaynig, V., Longair, M., Pietzsch, T., et al. (2012). Fiji: an open-source platform for biological-image analysis. Nat. Methods 9, 676-682. doi: 10.1038/nmeth.2019

Schubert, F. R., Tremblay, P., Mansouri, A., Faisst, A. M., Kammandel, B., Lumsden, A., et al. (2001). Early mesodermal phenotypes in splotch suggest a role for Pax3 in the formation of epithelial somites. Dev. Dyn. 222, 506-521. doi: 10.1002/dvdy.1211

Schultz, E., Gibson, M. C., and Champion, T. (1978). Satellite cells are mitotically quiescent in mature mouse muscle: an EM and radioautographic study. J. Exp. Zool. 206, 451-456. doi: 10.1002/jez.1402060314

Seale, P., and Rudnicki, M. A. (2000). A new look at the origin, function, and "stem-cell" status of muscle satellite cells. Dev. Biol. 218, 115-124. doi: 10.1006/dbio.1999.9565

Seger, C., Hargrave, M., Wang, X., Chai, R. J., Elworthy, S., and Ingham, P. W. (2011). Analysis of Pax7 expressing myogenic cells in zebrafish muscle development, injury, and models of disease. Dev. Dyn. 240, 2440-2451. doi: $10.1002 /$ dvdy. 22745

Shinin, V., Gayraud-Morel, B., Gomès, D., and Tajbakhsh, S. (2006). Asymmetric division and cosegregation of template DNA strands in adult muscle satellite cells. Nat. Cell Biol. 8, 677-687. doi: 10.1038/ ncb1425

Srivastava, S., Mishra, R. K., and Dhawan, J. (2010). Regulation of cellular chromatin state: insights from quiescence and differentiation. Organogenesis 6 , 37-47. doi: 10.4161/org.6.1.11337

Stoiber, W., and Sänger, A. M. (1996). An electron microscopic investigation into the possible source of new muscle fibres in teleost fish. Anat. Embryol. 194, 569-579. doi: 10.1007/BF00187470

Thisse, C., and Thisse, B. (2008). High-resolution in situ hybridization to whole-mount zebrafish embryos. Nat. Protoc. 3, 59-69. doi: 10.1038/nprot. 2007.514

Torrente, Y., Belicchi, M., Sampaolesi, M., Pisati, F., Meregalli, M., D’Antona, G., et al. (2004). Human circulating AC133(+) stem cells restore dystrophin expression and ameliorate function in dystrophic skeletal muscle. J. Clin. Invest. 114, 182-195. doi: 10.1172/JCI20325

Von Maltzahn, J., Jones, A. E., Parks, R. J., and Rudnicki, M. A. (2013). Pax7 is critical for the normal function of satellite cells in adult skeletal muscle. Proc. Natl. Acad. Sci. U.S.A. 110, 16474-16479. doi: 10.1073/pnas.1307680110 
Weber, C. M., Martindale, M. Q., Tapscott, S. J., and Unguez, G. A. (2012). Activation of Pax7-positive cells in a non-contractile tissue contributes to regeneration of myogenic tissues in the electric fish S. macrurus. PLoS ONE 7:e36819. doi: 10.1371/journal.pone. 0036819

Weinberg, E. S., Allende, M. L., Kelly, C. S., Abdelhamid, A., Murakami, T., Andermann, P., et al. (1996). Developmental regulation of zebrafish MyoD in wild-type, no tail and spadetail embryos. Development 122, 271-280.

Westerfield, M. (2000). The Zebrafish Book: A Guide for the Laboratory Use of Zebrafish (Danio Rerio). Eugene, OR: University of Oregon Press.

White, R. M., Sessa, A., Burke, C., Bowman, T., Leblanc, J., Ceol, C., et al. (2008). Transparent adult zebrafish as a tool for in vivo transplantation analysis. Cell Stem Cell 2, 183-189. doi: 10.1016/j.stem.2007. 11.002

Wood, A. J., and Currie, P. D. (2014). Analysing regenerative potential in zebrafish models of congenital muscular dystrophy. Int. J. Biochem. Cell Biol. 56, 30-37. doi: 10.1016/j.biocel.2014.10.021
Zammit, P. S., Golding, J. P., Nagata, Y., Hudon, V., Partridge, T. A., and Beauchamp, J. R. (2004). Muscle satellite cells adopt divergent fates: a mechanism for self-renewal? J. Cell Biol. 166, 347-357. doi: $10.1083 /$ jcb. 200312007

Zhang, H., and Anderson, J. E. (2014). Satellite cell activation and populations on single muscle-fiber cultures from adult zebrafish (Danio rerio). J. Exp. Biol. 217, 1910-1917. doi: $10.1242 /$ jeb. 102210

Conflict of Interest Statement: The authors declare that the research was conducted in the absence of any commercial or financial relationships that could be construed as a potential conflict of interest.

Copyright ( $\odot 2015$ Knappe, Zammit and Knight. This is an open-access article distributed under the terms of the Creative Commons Attribution License (CC BY). The use, distribution or reproduction in other forums is permitted, provided the original author(s) or licensor are credited and that the original publication in this journal is cited, in accordance with accepted academic practice. No use, distribution or reproduction is permitted which does not comply with these terms. 